\title{
MARINER 6 AND 7 TELEVISION PICTURES:
}

\section{PRELIMINARY ANALYSIS*}

\author{
R. B. LEIGHTON, N. H. HOROWITZ, B. C. MURRAY, R. P. SHARP \\ California Institute of Technology, Pasadena, Calif., U.S.A.
}

A. H. HERRIMAN and A. T. YOUNG

Jet Propulsion Laboratory, Pasadena, Calif., U.S.A.

B. A. SMITH

New Mexico State University, Las Cruces, N.M., U.S.A.

M. E. DA VIES

RAND Corporation, Santa Monica, Calif., U.S.A.

and

C. B. LEOVY

University of Washington, Seattle, U.S.A.

Before the space era, Mars was thought to be like the earth; after Mariner 4, Mars seemed to be like the moon; Mariners 6 and 7 have shown Mars to have its own distinctive features, unknown elsewhere within the solar system.

The successful flyby of Mariner 4 past Mars in July 1965 opened a new era in the close-range study of planetary surfaces with imaging techniques. In spite of the limited return of data, Mariner 4 established the basic workability of one such technique, which involved use of a vidicon image tube, on-board digitization of the video signal, storage of the data on magnetic tape, transmission to the earth at reduced bit rate by way of a directional antenna, and reconstruction into a picture under computer control. Even though the Mariner 4 pictures covered only about $1 \%$ of Mars's area, they contributed significantly to our knowledge of that planet's surface and history $[1,2,15,17]$.

The objectives of the Mariner 6 and 7 television experiment were to apply the successful techniques of Mariner 4 to further explore the surface and atmosphere of Mars, both at long range and at close range, in order to determine the basic character of features familiar from ground-based telescopic studies; to discover possible further clues as to the internal state and past history of the planet; and to provide information germane to the search for extraterrestrial life.

The Mariner 6 and 7 spacecraft successfully flew past Mars on 31 July and 5 August 1969 , respectively; first results of the television experiment, based upon qualitative study of the uncalibrated pictures, have been reported [3,4]. The purpose of this article is to draw together the preliminary television results from the two spacecraft; to present tentative data concerning crater size distributions, wall slopes, and geographic distribution; to discuss evidences of haze or clouds; to describe new, distinctive types of topography seen in the pictures; and to discuss the implications of the results with respect to the present state, past history, and possible biological status of Mars.

* Reprinted from Science 166, No. 3901, 3 October 1969. 
The data presented here and in the two earlier reports were obtained from inspection and measurement of a partial sample of pictures in various stages of processing. As such, the results must be regarded as tentative, subject to considerable expansion and possible modification as more complete sets, and better-quality versions, of the pictures become available over a period of several months. They are offered at this time because of their unique nature, their wide interest, and their obvious relevance to the forthcoming Mariner 1971 (orbiter) and Viking 1973 (lander) missions.

\section{Television System Design}

The experience and results of Mariner 4 strongly influenced the basic design of the Mariner 6 and 7 television experiment. The earlier pictures showed Mars to be heavily cratered, but to have subdued surface relief and low photographic contrast, and possibly to have a hazy atmosphere. It was also found that a vidicon-type camera tube has a most important property: the 'target noise', analogous to photographic grain, is less than that of a photographic emulsion by perhaps a factor of 10 [2] and is the same from picture to picture. Thus the 64-level (6-bit) encoding scheme of Mariner 4 was able to cope with the extremely low contrast conditions because intensity calibration and contrast enhancement by computer techniques could be effectively applied to the data to produce pictures of useful quality.

Early design studies for Mariner 6 and 7 centered around 256-level (8-bit) encoding - at least a tenfold increase in data return over that from Mariner 4; overlapping twocolor coverage along the picture track (similar to that of Mariner 4); use of two cameras of different focal lengths to provide higher-resolution views of areas nested within overlapping, wider-angle frames; and use of the camera of longer focal length to obtain a few full-disk photographs showing all sides of Mars as the spacecraft approached the planet. A third filter color, 'blue', was added to the 'red' and 'green' of Mariner 4 for the purpose of studying atmospheric effects.

Limitations of volume, money, and schedule prevented use of a suitable digital recorder system with the necessary data storage capacity, but, through a hybrid system which uses both digital and analog tape recorders, it appeared possible to achieve sufficient data storage capacity, albeit at the expense of complexity.

In its final form, the television experiment employed a two-camera system in which the picture formats and electronic circuits of the cameras were identical (for economy and for efficient use of the tape recorders); a digital tape recorder to store the six lowestorder bits of an 8-bit encoded word for every seventh picture element ('pixel') along each TV picture line (referred to as $1 / 7$ digital data), ${ }^{*}$ and a second, similar tape recorder to store analog data for all pixels [5].

In order to reduce the 'noise' introduced by analog recording, the average signal level was held nearly constant and the modulation index was increased by automatic gain control (AGC) and a cube-law 'contrast enhancement' circuit. This signal

* The $1 / 7$ digital TV data for the central $20 \%$ of each line were replaced by encoded data from other on-board experiments. In this region, coarser, $1 / 28$ digital data (6-bit-encoded for every 28 th pixel), stored on the analog tape recorder, were available (see Figure 2). 
processing increased the data return by a factor of about 5 ; it also made necessary an elaborate program of computer restoration of the pictorial data after receipt on the earth.

Some technical data relating to the camera system are given in Leighton et al. [3], and more complete data will be given elsewhere [5]. Briefly, one camera, called camera A, has a field of view $11^{\circ} \times 14^{\circ}$ and a rotary shutter which carries four colored filters in the sequence red, green, blue, green, and so on. Alternating exposures with camera $\mathrm{A}$ is camera $\mathrm{B}$, which has a focal length 10 times as great and a field of view $1.1 \times 1.4$. Camera B carries only a minus-blue haze filter.

Certain further aspects of the camera-operation and on-board signal processing are shown in Figures 1 and 2. Figure 1 shows the cameras mounted on the spacecraft.

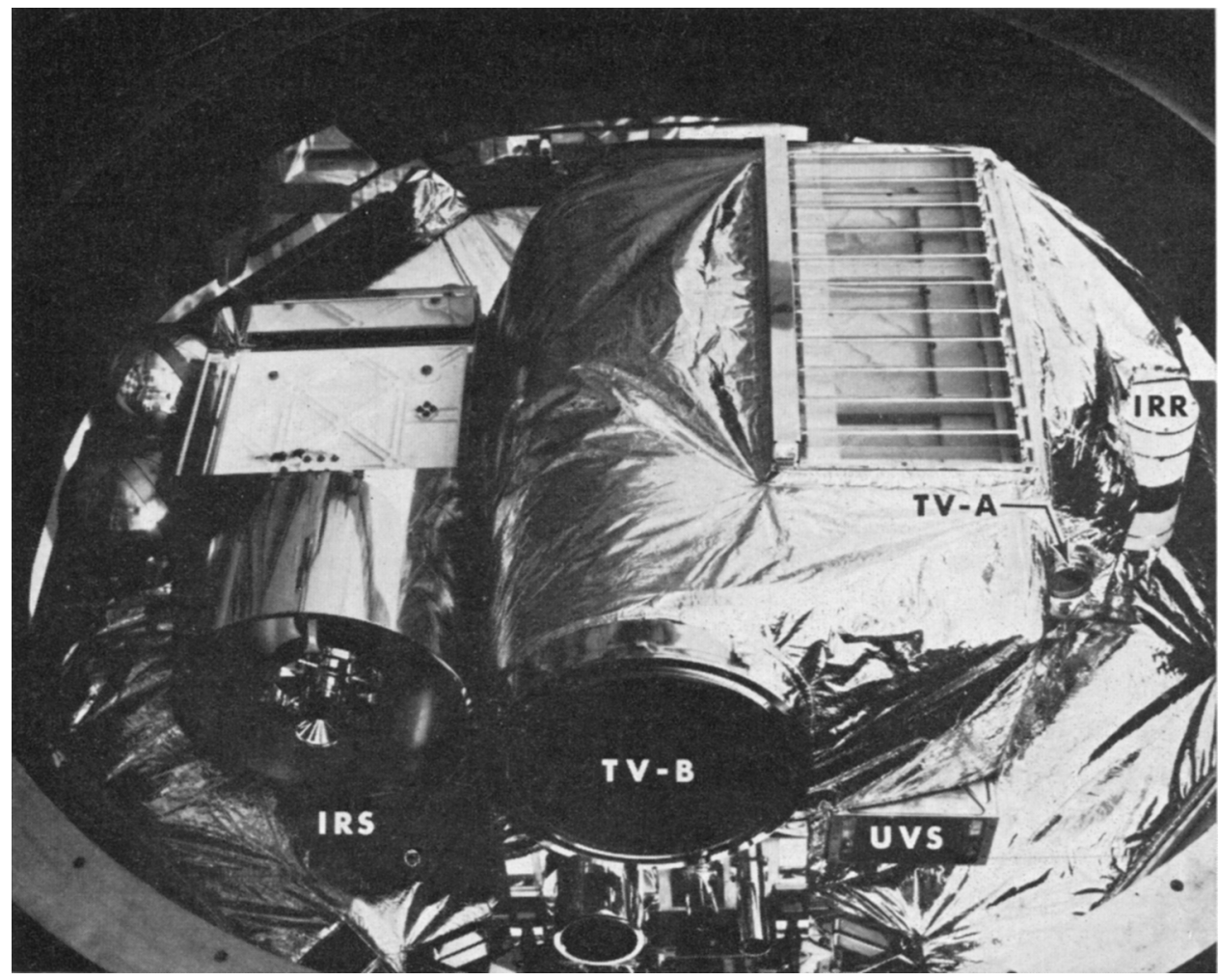

Fig. 1. Mariner 6 instruments and scan platform, mounted on the spacecraft. The five principal instruments are an infrared spectrometer (IRS), television camera B (TV-B), an ultraviolet spectrometer (UVS), television camera A (TV-A), and an infrared radiometer (IRR).

Figure 2a shows the effect of automatic gain control on the analog signal, an effect similar to that of a high-pass filter in that it diminishes the amplitude of long-spatialwavelength (low-frequency) signals. The response time of the AGC, about 6 millisec, corresponds to about one-tenth of a picture line, and its characteristic effects are apparent in all near-encounter pictures, especially those of high contrast: the polar cap boundary, the planet limb, and the terminator. 


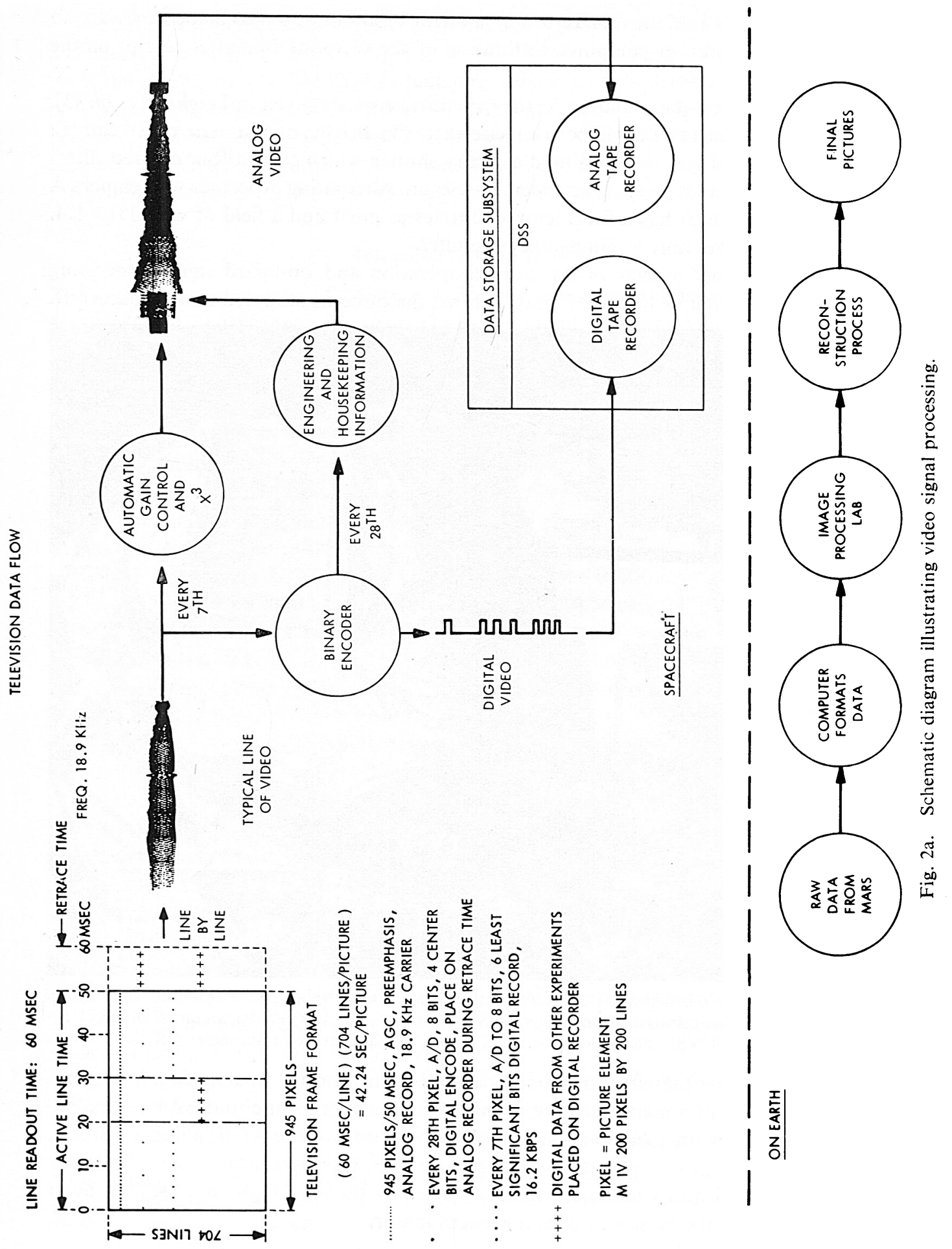




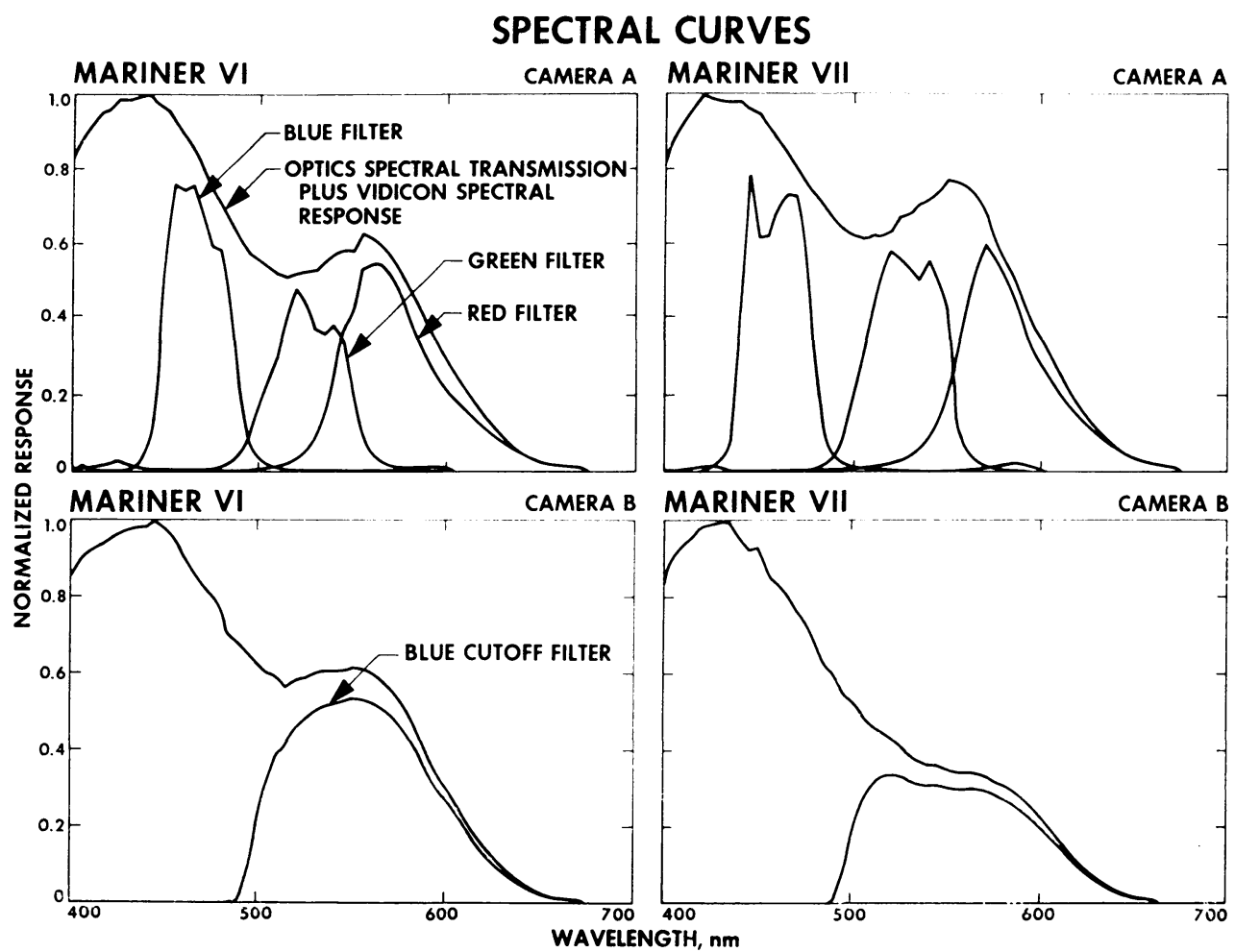

Fig. 2b. Spectral sensitivity curves of Mariner 6 and 7 cameras, with and without filters.

To illustrate the nature of the picture restoration process, we list some of the steps in the computer reduction: Restore the two highest-order bits to the digital data*; remove effects of AGC and 'cuber' in the analog data; combine digital and analog data; measure and remove electronic 'pickup' noise*; measure pixel locations of reseau marks on flight pictures and calibration pictures [6]; bring pictorial calibration and flight data, by interpolation, into agreement with the known reseau pattern; measure and correct for optical distortions; measure and remove effects of residual image from calibration and flight data; evaluate the sensitometric response of each pixel from calibration data and deduce the true photometric exposure for each flight pixel **; correct for the effects of shutter-speed variations and light leakage (camera B); and evaluate and correct for the modulation-transfer function of the camera system. Some of these steps have been applied to a few of the flight pictures on an experimental, ad hoc basis, pending receipt of complete, corrected telemetry data from the six playbacks of the recorded close-up pictures.

* This procedure is semiautomatic, subject to hand correction by the computer operator as necessary.

** For each spacecraft, this must be done for each filter of each camera and for all calibration temperatures, and the results must be corrected to the observed flight temperature. 


\section{Mission Design and Television Data Return}

As was described in Leighton et al. [3], the planetary encounter period for each spacecraft was divided into two parts: a far-encounter (FE) period beginning 2 or 3 days prior to, and extending to within a few hours of, closest approach, and a near-encounter (NE) period bracketing the time of closest approach.

As the Mariner 6 and 7 mission was originally conceived, the analog data for eight FE B-camera pictures and $25 \mathrm{NE}$ pictures, and the 1/7 digital NE picture data (and other NE science data) were to be recorded and later transmitted to the earth at 270 bits per second over a 5-day period for each spacecraft. However, a 60 -fold increase in transmission rate was realized during the development of the spacecraft, so that realtime transmission of the $1 / 7$ digital data stream, or of the digitized analog data during picture playback, became possible. This capability thus led to the extended FE picture sequences actually used, in which the analog tape recorder was filled and played back several times. In addition, several hundred 1/7 digital pictures were transmitted directly to the earth in real time. Some of these digital pictures, taken during the very late FE period of Mariner 7, contain valuable three-color camera-A photometric data for large areas of Mars at a resolution greatly superior to that attainable from the earth. In all, $50 \mathrm{FE}$ pictures, $26 \mathrm{NE}$ pictures, and 428 useful* real-time 1/7 digital pictures were returned from Mariner 6, and 93 FE pictures, 33 NE pictures, and 749 useful real-time digital pictures were returned from Mariner 7 . This further ninefold increase in the number of FE pictures and $18 \%$ increase in the number of NE pictures over the original plan represents a total data return 200 times that of Mariner 4, not counting the real-time digital frames.

The pictures are designated by spacecraft, camera mode, and frame number. Thus ' 6 N17' means Mariner 6 NE frame 17; '7F77' means Mariner 7 FE frame 77; and so on. The first NE picture from each spacecraft was a camera-A, blue-filter picture. Thus, in near-encounter, all odd-numbered frames are camera-A (wide-angle, low-resolution) frames.

During each day of the FE period, camera B was used to record a series of up to 33 full-disk analog pictures of Mars with the AGC clamped. These pictures were transmitted to the earth during each daily period when the 16.2-kilobits-per-second signal could be received by the 210 -foot antenna of the Goldstone, California, station of the NASA deep-space net. These pictures showed all sides of the planet as it rotated each day, and, within the total 5-day series, each face of Mars was recorded at a number of different scales and under many different viewing conditions. The phase angle was nearly consant throughout the far-encounter for both spacecraft $\left(25^{\circ}\right.$, morning terminator visible).

The approximate near-encounter picture locations for the two spacecraft are shown in Figure 3, and the relevant data are given in Tables I and II. The picture tracks were chosen, in concert with investigators for other on-board experiments, on the basis of several considerations and constraints. First, the choice of possible arrival dates was

* Most of the real-time FE A-camera digital pictures were of no value because little or none of the image projected outside the central $20 \%$ blank area. 
TABLE I

Mariner 6 near-encounter picture data at center of frame

\begin{tabular}{lllllll}
\hline $\begin{array}{l}\text { Picture } \\
\text { No. }\end{array}$ & $\begin{array}{llll}\text { Slant } \\
\text { range } \\
(\mathrm{km})\end{array}$ & $\begin{array}{l}\text { View } \\
\text { angle } \\
\text { from } \\
\text { vertical } \\
(\mathrm{deg})\end{array}$ & $\begin{array}{l}\text { Solar } \\
\text { zenith } \\
\text { angle } \\
(\mathrm{deg})\end{array}$ & $\begin{array}{l}\text { Latitude } \\
(\mathrm{deg})\end{array}$ & $\begin{array}{l}\text { East } \\
\text { longitude } \\
(\mathrm{deg})\end{array}$ & $\begin{array}{l}\text { Area } \\
(\text { 'height } \times \text { width }) \\
(\mathrm{km})\end{array}$ \\
& & & & & \\
\end{tabular}

\begin{tabular}{rllclll}
\hline 1 & \multicolumn{7}{c}{ Center of picture dos not intercept planet } & Limb \\
2 & 7401 & 70.2 & 18.8 & 4.3 & 292.3 & $157.2 \times 556.4$ \\
3 & 6614 & 57.3 & 6.8 & -2.0 & 303.2 & Limb \\
4 & 6130 & 49.8 & 4.9 & -5.2 & 310.3 & $125.6 \times 229.1$ \\
5 & 5682 & 41.8 & 11.1 & -8.6 & 317.3 & Limb \\
6 & 5348 & 36.2 & 17.1 & -10.6 & 323.0 & $109.1 \times 158.7$ \\
7 & 5028 & 29.7 & 23.5 & -12.9 & 329.1 & $1112 \times 1597$ \\
8 & 4777 & 25.2 & 28.9 & -14.1 & 334.4 & $97.4 \times 125.7$ \\
9 & 4920 & 40.5 & 41.3 & -0.1 & 346.0 & $1679 \times 1861$ \\
10 & 4737 & 39.4 & 45.8 & -1.2 & 350.7 & $119.1 \times 122.1$ \\
11 & 4558 & 38.1 & 50.8 & -2.7 & 355.8 & $1309 \times 1378$ \\
12 & 4439 & 38.8 & 55.6 & -3.0 & 0.6 & $113.9 \times 108.4$ \\
13 & 4333 & 39.6 & 60.9 & -3.7 & 5.8 & $1191 \times 1243$ \\
14 & 4832 & 59.5 & 20.5 & -13.0 & 324.8 & $99.8 \times 231.4$ \\
15 & 4382 & 49.3 & 30.6 & -15.9 & 334.7 & Limb \\
16 & 4103 & 42.1 & 38.2 & -17.3 & 342.3 & $83.7 \times 132.8$ \\
17 & 3868 & 34.6 & 45.7 & -18.5 & 349.9 & $858 \times 1289$ \\
18 & 3738 & 30.3 & 52.1 & -16.6 & 356.6 & $77.1 \times 102.5$ \\
19 & 3613 & 24.4 & 58.5 & -16.9 & 3.1 & $773 \times 1036$ \\
20 & 3543 & 20.4 & 64.2 & -16.6 & 8.9 & $73.1 \times 88.8$ \\
21 & 3498 & 16.3 & 70.3 & -16.2 & 15.1 & $723 \times 929$ \\
22 & 3497 & 14.9 & 75.8 & -15.2 & 20.5 & $72.3 \times 84.4$ \\
23 & 3522 & 15.0 & 81.7 & -14.2 & 26.4 & $718 \times 921$ \\
24 & 3584 & 17.6 & 87.2 & -12.7 & 31.7 & $74.8 \times 87.0$ \\
25 & 3622 & 19.1 & 90.0 & -12.1 & 34.4 & $765 \times 973$ \\
26 & 3680 & 21.3 & 93.0 & -11.0 & 37.3 & $77.4 \times 91.1$ \\
& & & & & & \\
\hline
\end{tabular}

limited by engineering considerations to the interval 31 July to 15 August 1969 . Second, on any given arrival date, the time of closest approach was limited to an interval of about $1 \mathrm{~h}$ by the requirement that the spacecraft be in radio view of Goldstone tracking station during a period of several hours which bracketed the time of closest approach. These two constraints and the approximate 24-h rotation period of Mars considerably limited the possible longitudes of Mars that could effectively be viewed; in particular, the most prominent dark area, Syrtis Major, could not be seen under optimum conditions. Fortunately, Meridiani Sinus, a prominent dark area almost as strong and permanent as Syrtis Major, and various other important features well known from earth observation, were easily accessible.

The cameras and other instruments were mounted on a two-axis 'scan platform' which could be programmed to point the instruments in as many as five successive directions during the near-encounter. The particular orbit and platform-pointing strategy adopted for each spacecraft was designed to achieve the best possible return 
of scientific data within a context of substantial commonality but with some divergence of needs of the various experiments. The television experimenters placed great weight upon viewing a wide variety of classical features, including the polar cap; continuity of picture coverage; substantial two-color overlap and some three-color overlap is possible; stereoscopic overlap; viewing the planet limb in blue light; viewing the same area at two different phase angles; and seeing the same area under different viewing conditions at nearly the same phase angle.

The Mariner 6 picture track was chosen to cover a broad longitude range at low latitudes in order to bring into view a number of well-studied transitional zones

TABLE II

Mariner 7 near-encounter picture data at center of frame

\begin{tabular}{|c|c|c|c|c|c|c|}
\hline $\begin{array}{l}\text { Picture } \\
\text { No. }\end{array}$ & $\begin{array}{l}\text { Slant } \\
\text { range } \\
(\mathrm{km})\end{array}$ & $\begin{array}{l}\text { View } \\
\text { angle } \\
\text { from } \\
\text { vertical } \\
\text { (deg) }\end{array}$ & $\begin{array}{l}\text { Solar } \\
\text { zenith } \\
\text { angle } \\
(\text { deg) }\end{array}$ & $\begin{array}{l}\text { Latitude } \\
\text { (deg) }\end{array}$ & $\begin{array}{l}\text { East } \\
\text { longitude } \\
\text { (deg) }\end{array}$ & $\begin{array}{l}\text { Area } \\
\text { ('height } \times \text { width') } \\
(\mathrm{km})\end{array}$ \\
\hline
\end{tabular}

\begin{tabular}{|c|c|c|c|c|c|c|}
\hline 1 & \multicolumn{5}{|c|}{ Center of picture does not intercept planet } & Limb \\
\hline 2 & \multicolumn{5}{|c|}{ Center of picture does not intercept planet } & Limb \\
\hline 3 & 9243 & 69.6 & 25.8 & 14.4 & 350.3 & Limb \\
\hline 4 & 8533 & 59.7 & 15.6 & 5.3 & 354.9 & $175.3 \times 412.5$ \\
\hline 5 & 7993 & 52.3 & 8.2 & -1.4 & 357.7 & Limb \\
\hline 6 & 7533 & 46.1 & 2.5 & -7.0 & 1.3 & $152.9 \times 262.0$ \\
\hline 7 & 7129 & 40.6 & 4.7 & -12.0 & 3.8 & Limb \\
\hline 8 & 6771 & 35.8 & 10.2 & -16.4 & 7.3 & $137.7 \times 200.4$ \\
\hline 9 & 6443 & 31.4 & 15.1 & -20.5 & 10.0 & $1503 \times 2233$ \\
\hline 10 & 6654 & 47.5 & 50.5 & -53.1 & 328.3 & $197.0 \times 165.7$ \\
\hline 11 & 6377 & 45.6 & 52.1 & -57.1 & 332.4 & $2282 \times 1672$ \\
\hline 12 & 6084 & 42.9 & 53.4 & -60.6 & 338.9 & $166.6 \times 147.5$ \\
\hline 13 & 5864 & 42.4 & 55.9 & -64.2 & 344.1 & $2049 \times 1912$ \\
\hline 14 & 5631 & 41.1 & 58.2 & -67.4 & 352.3 & $148.8 \times 139.4$ \\
\hline 15 & 5462 & 41.9 & 61.4 & -70.7 & 0.1 & $2098 \times 2058$ \\
\hline 16 & 5285 & 42.1 & 64.5 & -73.2 & 12.5 & $137.4 \times 138.9$ \\
\hline 17 & 5167 & 44.2 & 68.3 & -75.9 & 26.6 & $1368 \times 1561$ \\
\hline 18 & 5049 & 45.8 & 72.1 & -76.8 & 46.3 & $131.69 \times 147.2$ \\
\hline 19 & 4994 & 49.2 & 76.7 & -77.3 & 68.6 & $1343 \times 1862$ \\
\hline 20 & 4949 & 52.4 & 81.4 & -75.4 & 89.4 & $133.5 \times 171.7$ \\
\hline 21 & 5314 & 65.7 & 14.0 & -20.6 & 6.1 & Limb \\
\hline 22 & 4776 & 55.0 & 24.9 & -28.5 & 14.2 & $97.9 \times 201.3$ \\
\hline 23 & 4405 & 46.8 & 33.3 & -34.3 & 21.2 & $1383 \times 2488$ \\
\hline 24 & 4130 & 39.9 & 40.7 & -38.3 & 28.8 & $84.5 \times 128.9$ \\
\hline 25 & 3917 & 33.7 & 47.3 & -41.7 & 36.2 & $874 \times 1291$ \\
\hline 26 & 3759 & 28.4 & 53.6 & -43.7 & 44.2 & $77.2 \times 101.4$ \\
\hline 27 & 3638 & 23.6 & 59.5 & -45.3 & 52.0 & $775 \times 1035$ \\
\hline 28 & 3664 & 28.1 & 65.6 & -40.4 & 62.1 & $80.7 \times 92.2$ \\
\hline 29 & 3619 & 26.6 & 71.1 & -40.4 & 69.3 & $823 \times 995$ \\
\hline 30 & 3621 & 27.3 & 76.7 & -39.1 & 76.3 & $81.5 \times 87.7$ \\
\hline 31 & 3646 & 28.4 & 82.1 & -37.7 & 83.1 & $831 \times 987$ \\
\hline 32 & 3722 & 31.6 & 87.7 & -35.0 & 89.5 & $87.1 \times 90.8$ \\
\hline 33 & 3822 & 34.9 & 93.4 & -32.2 & 95.5 & $996 \times 1116$ \\
\hline
\end{tabular}




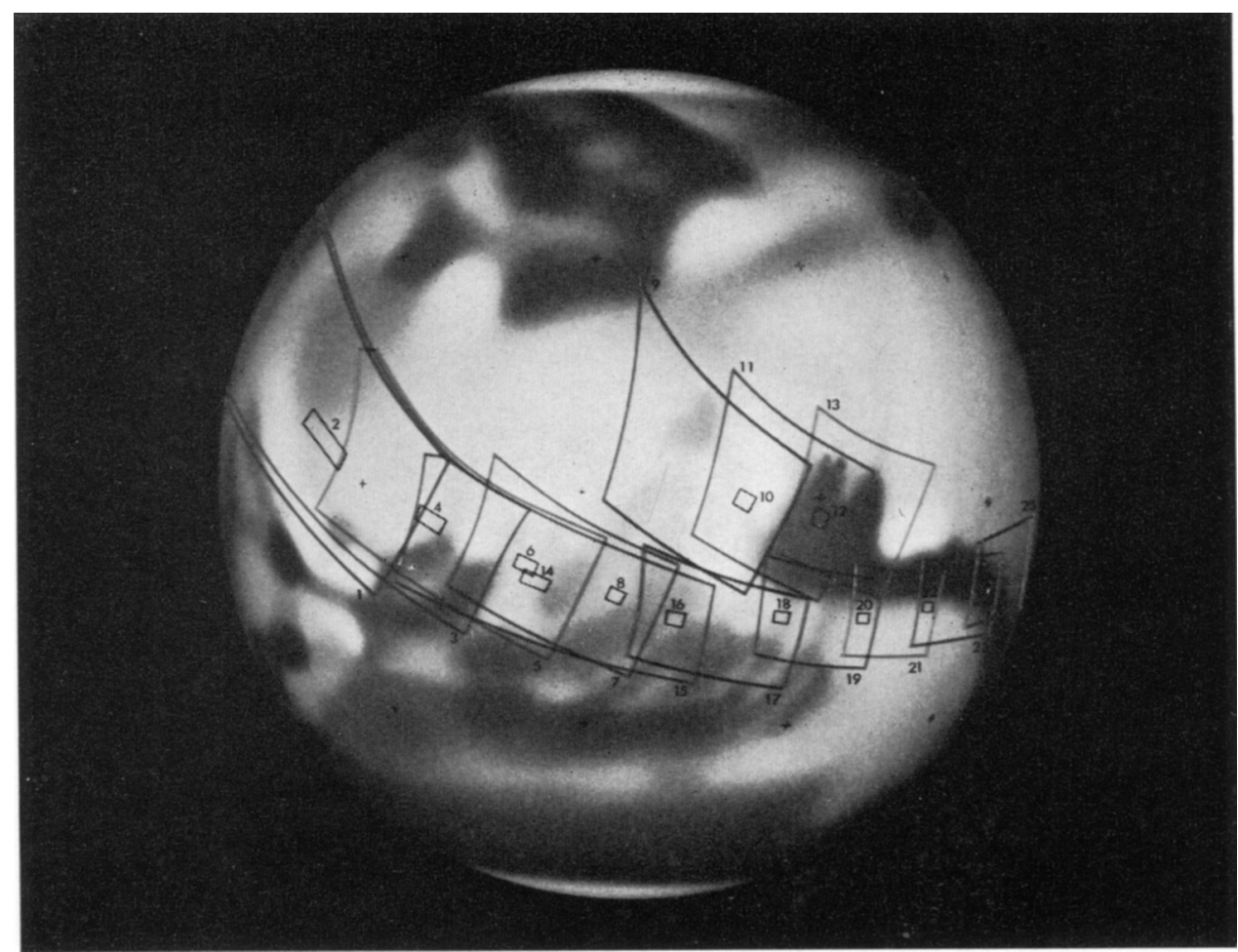

Fig. 3a. Mariner 6 NE picture locations, plotted on a painted globe of Mars. The first picture is taken with a blue filter. The camera-A filter sequence is blue, green, red, green, and so on. Wideangle (camera A) frames and narrow-angle (camera B) frames alternate.

between light and dark areas, two 'oases' (Juventae Fons and Oxia Palus), and a variable light region (Deucalionis Regio). The picture track of Mariner 7 was selected so that it would cross that of Mariner 6 on the dark area Meridiani Sinus, thereby providing views of that important region under different lighting conditions. The track was also specifically arranged to include the south polar cap and cap edge, to intersect the 'wave-of-darkening' feature Hellespontus, and to cross the classical bright circular desert Hellas.

\section{Camera Operation and Picture Appearance}

With minor exceptions, both camera systems operated normally, well within expected ranges of the various ambient parameters. The principal exceptions were the following: the contrast of the FE pictures of Mariner 6 was lower than expected, because of an unaccountably low signal level; the electronic 'pickup' noise from the square-wave power system was somewhat greater than anticipated for both spacecraft; the first track of the Mariner 6 analog tape recorder showed a $50 \%$ drop in amplifier gain between FE and NE playback; and the fourth track of the analog tape recorder of Mariner 7 showed greater than normal 'dropout' noise. These deficiencies not only affected the subjective appearance of the pictures but also necessitate more elaborate 


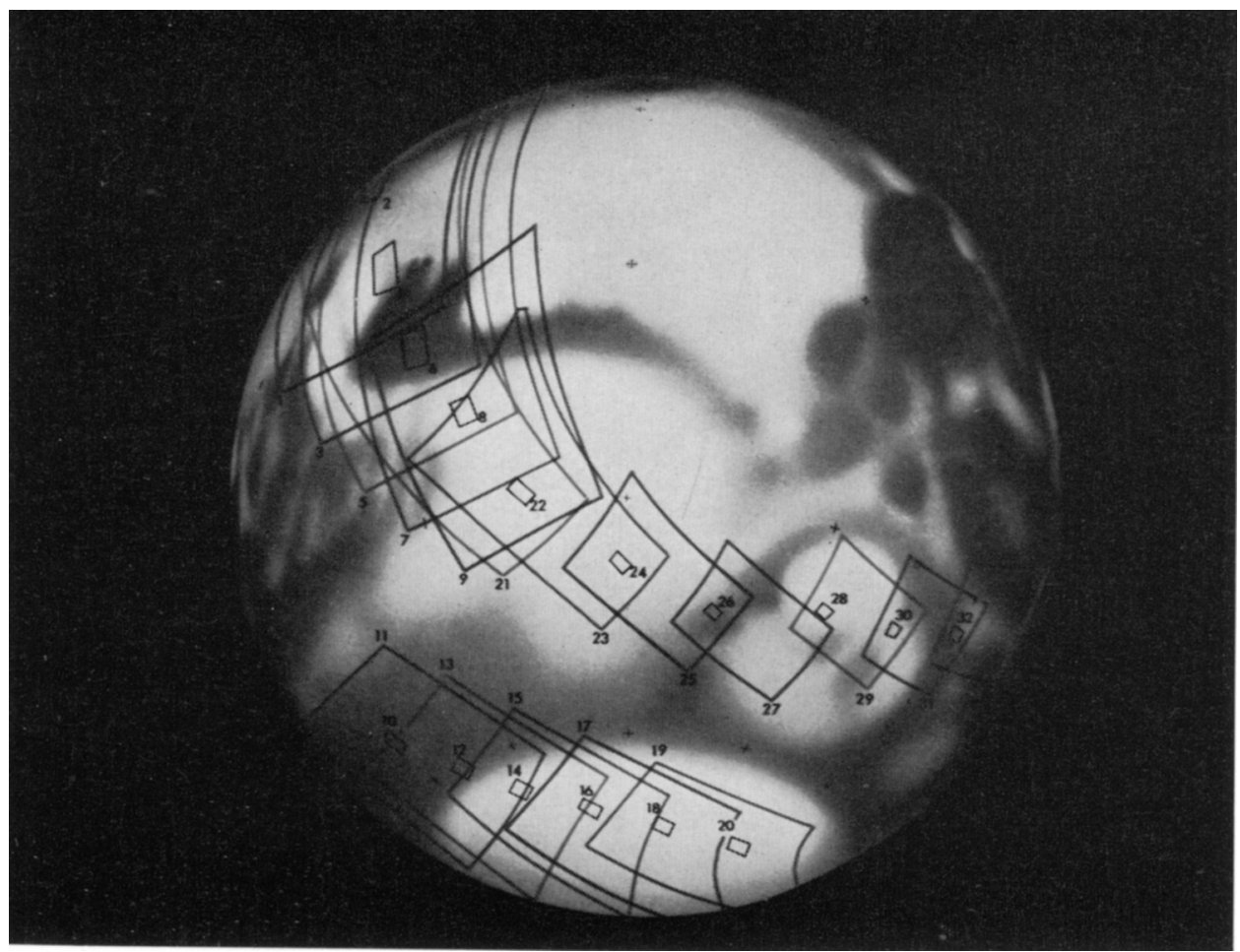

Fig. 3b. Mariner 7 NE picture locations. The filter sequence is the same as for Mariner 6.

processing of the data before accurate, high-resolution photometric measurements can be made.

The first impression of Mars conveyed by the pictures is that the surface is generally visible and is not obscured by clouds or haze except perhaps in the polar regions and in a few areas marked by the appearance of afternoon 'clouds'. The classical martian features stand out clearly in the far-encounter pictures, and, as the image grows, these features transform into areas having recognizable relationships to the numerous craters which mark the surface. The near-encounter pictures seem to show a Moon-like terrain. However, one must bear in mind the fact that the camera system was designed to enhance the contrast of local brightness fluctuations by a factor of 3 , and that the contrast of the pictures is often further enhanced in printing. Actually, although the surface is generally visible, its contrast is much less than that of the moon under similar lighting conditions. Fewer shadows are seen near the terminator.

The determination of true surface contrast depends critically upon the amount of haze or veiling glare in the picture field. Although the pictures appear to be free of such effects, more refined photometric measurements may well reveal the presence of veiling glare or a general atmospheric haze. Definite conclusions must await completion of the photometric reduction of the pictures, including corrections for vidicon dark current, residual images, shutter light leaks, and possible instrumental scattering. 


\section{Observed Atmospheric Features}

\section{A. AEROSOL SCATTERING}

Clear-cut evidence for scattering layers in the atmosphere is provided by the pictures of the north-eastern limb of Mariner 7. The limb appears in frames $7 \mathrm{~N} 1,2,3,5$, and 7, and in a few real-time digital A-camera frames received immediately prior to frame $7 \mathrm{~N} 1$. The limb appears again in frame $7 \mathrm{~N} 21$ after the platform slew which began the track across Hellas. Thus the limb coverage includes each of the filters of the A camera and one B-camera frame.

Several characteristics of the scattering layer shown in Figure 4 are evident even at this early stage. (i) The scattering is distinctly stratified in horizontal layers, just as scattering from aerosol layers in the earth's atmosphere is. (ii) The intensity of the scattering varies substantially over distances of a few hundred kilometers and is more intense toward the west or toward earlier local times of day. (iii) The thickness of the scattering layer is about $10 \mathrm{~km}$. (iv) The height of the layer is difficult to determine because of the difficulty of locating the true planetary limb, but it is estimated to be between 15 and $25 \mathrm{~km}$ in the region covered by frames $7 \mathrm{~N} 1$ to $7 \mathrm{~N} 7$ and up to $40 \mathrm{~km}$ in frame $7 \mathrm{~N} 21$. (v) The layer is about $50 \%$ brighter in the blue-filter pictures than in the red or green. This is less difference in intensity than would be expected for Rayleigh scattering, but corresponds more closely to $\lambda^{-2}$ wavelength dependence.
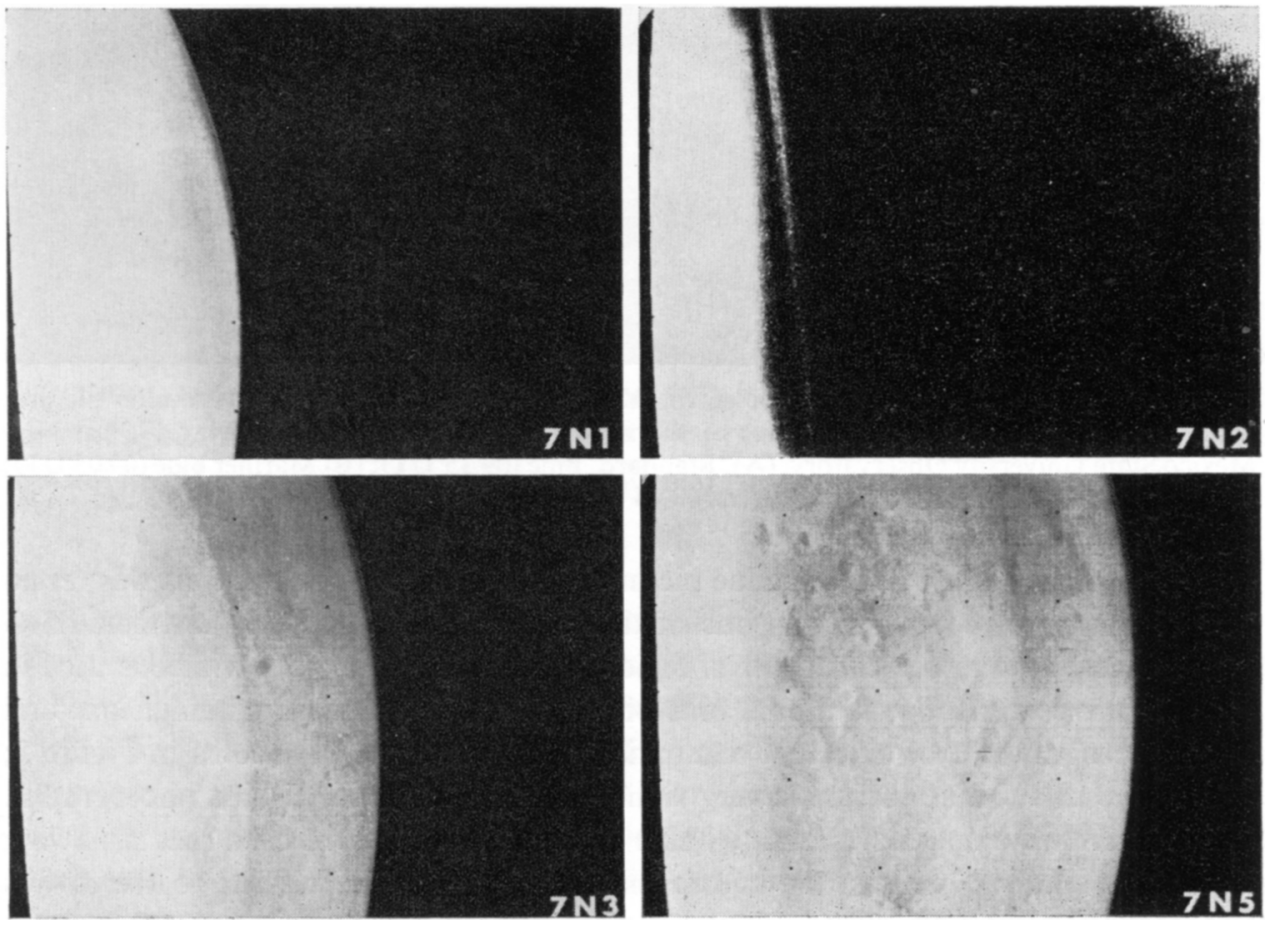

Fig. 4. Mariner 7 limb frames $7 \mathrm{N1}, 2,3$, and 5. Note the sharp haze layer adjacent to the limb in frames $7 \mathrm{~N} 1,3$, and 5, and the magnified view (tenfold magnification) in $7 \mathrm{~N} 2$. The prominent, cratered dark feature in frame $7 \mathrm{~N} 5$ is Meridiani Sinus. North is approximately toward the right. 
The relationship between this scattering layer and the martian tropopause is obviously of great interest and will be studied carefully as more refined data become available.

The normal-incidence optical depth, isotropic scattering being assumed, is estimated as 0.01 in the red and about 0.03 in the blue. $\mathrm{A} \lambda^{-2}$ dependence suggests that scattering should be predominantly forward, so these very small values should be underestimates.

The real-time digital data reveal an apparent limb haze near the south polar cap, and over the regions of Mare Hadriaticum and Ausonia just east of Hellas. The haze over these regions is not as bright as the haze discussed above, so it is unlikely that it is sufficiently dense to obscure surface features seen at NE viewing angles. A faint limb haze may also be present in the Mariner 6 limb frames.

\section{B. THE 'BLUE HAZE'}

Despite these evidences of very thin aerosol hazes, visible tangentially on the limb, there is no obscuring 'blue haze' sufficient to account for the normally poor visibility of dark surface features seen or photographed in blue light and for their occasional better visibility - the so-called 'blue-clearing' phenomenon $[7,8]$.
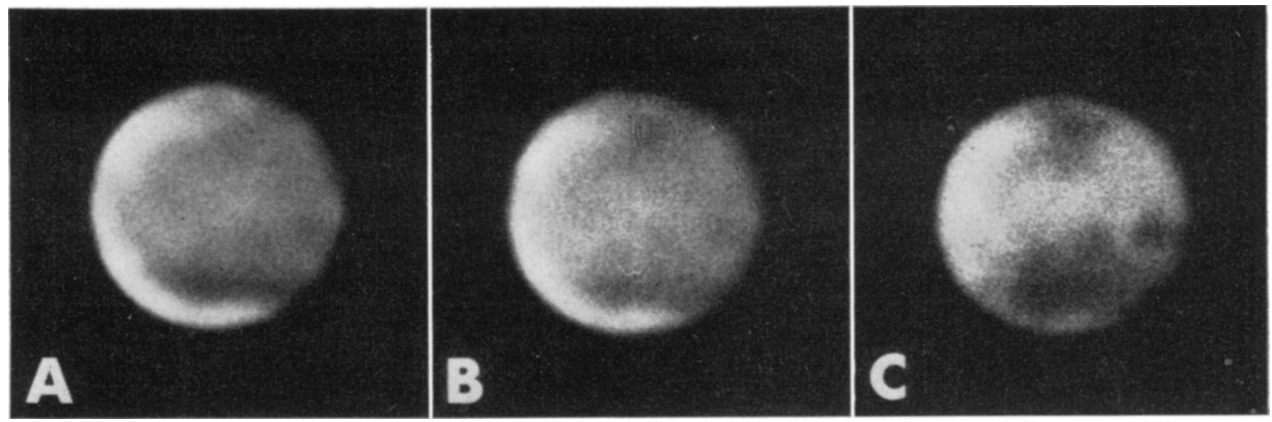

Fig. 5. Photographs of Mars from the earth, taken to compare Mariner-type blue-filter pictures with 'standard' green and blue pictures of Mars. The pictures were taken 24 May 1969 at New Mexico State University Observatory. (A) 'Standard' blue (09 15 UT); (B) Mariner blue (09 05 UT); (C) standard green (08 44 UT). North is at the top.

The suitability of the Mariner blue pictures for 'blue haze' observations was tested by photographing Mars through one of the Mariner blue filters on Eastman III-G plates, whose response in this spectral region is similar to that of the vidicons used in the Mariner camera. Conventional blue photographs on unsensitized emulsions and green photographs were taken for comparison. A typical result is shown in Figure 5; the simulated TV blue picture is very similar to the conventional blue photographs. The effective wavelength of the actual blue TV pictures should be even shorter, owing to a lower ambient temperature and to the absence of reddening due to the earth's atmosphere.

The blue pictures taken by Mariners 6 and 7 clearly show craters and other surface features, even near the limb and terminator, where atmospheric effects are strong. 


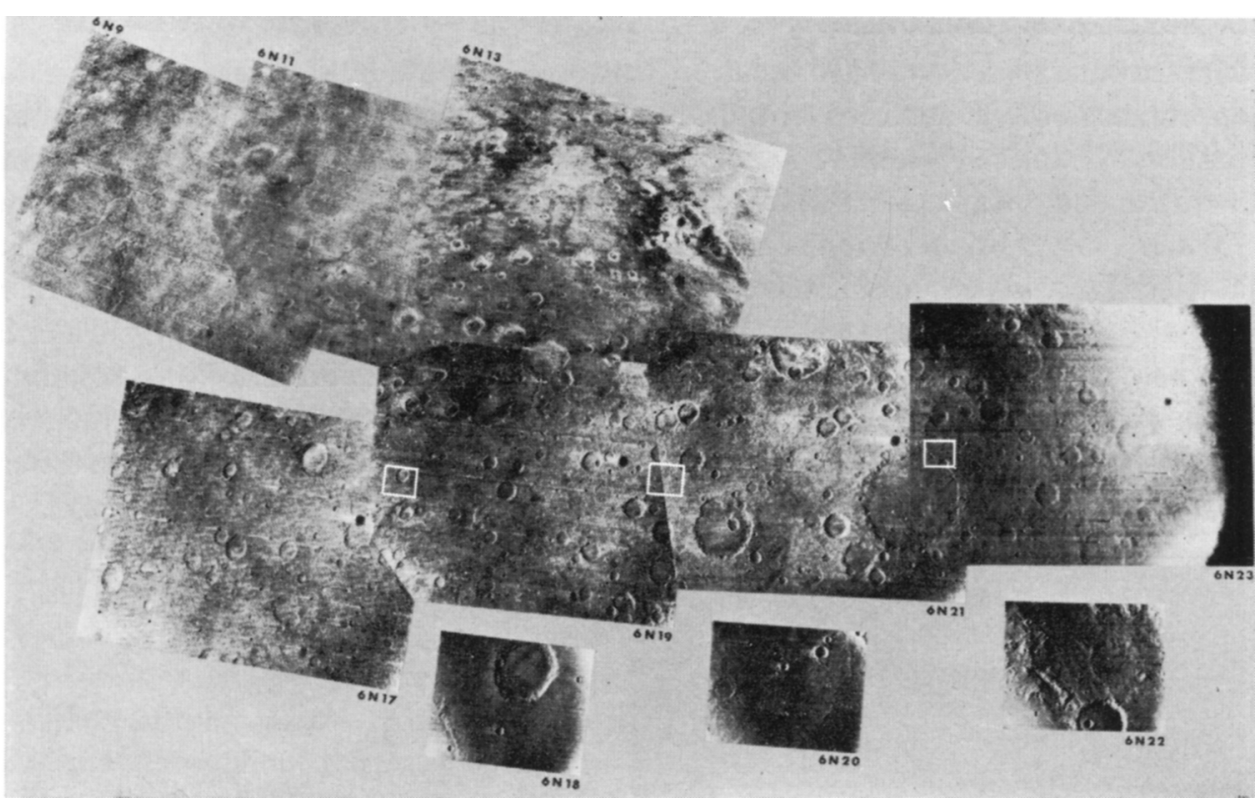

Fig. 6. Composite of ten Mariner 6 pictures showing cratered terrain in the areas of Margaritifer Sinus (top left), Meridiani Sinus (top center), and Deucalionis Regio (lower strip). Large-scale contrasts are suppressed by AGC and small-scale contrast is enhanced (see text). Craters are clearly visible in blue frames $6 \mathrm{~N} 9$ and $6 \mathrm{~N} 17$, but albedo variations are subdued. Locations of three cameraB frames are marked by rectangles. North is approximately toward the top, and the sunset terminator lies near the right edge of $6 \mathrm{~N} 23$.

Polar cap frame 7N17 shows sharp surface detail very near the terminator. The blue limb frame $6 \mathrm{~N} 1$ shows surface detail corresponding to that seen in the subsequent overlapping green frame 6N3. Figure 6 includes blue, green, and red pictures in the region of Sinus Meridiani. Although craters show clearly in all three colors, albedo variations, associated both with craters and with larger-scale features, are much more pronounced in green and red than in blue. Blue photographs obtained from the earth during the Mariner encounters show the normal 'obscured' appearance of Mars.

\section{SOUTH POLAR CAP SHADING}

Another possible indication of atmospheric haze is the remarkable darkening of the south polar cap near both limb and terminator in the FE pictures (Figure 7). This darkening is plainly not due to cloud or thick haze since, during near-encounter, surface features are clearly visible everywhere over the polar cap. It may be related to darkening seen in NE Mariner 7 frames near the polar cap terminator, and to the decrease in contrast with increasing viewing angle between the cap and the adjacent mare seen in frame 7N11 (Figure 8b). The darkening may be due to optically thin aerosol scattering over the polar cap, or possibly to unusual photometric behavior of the cap itself. In either case, it may be complicated by systematic diurnal or latitudinal effects. 
D. NORTH POLAR PHENOMENA

Marked changes seem to have occurred, between the flybys of Mariners 6 and 7, in the appearance of high northern latitudes. Some of these changes are revealed by a comparison of frames $6 \mathrm{~F} 34$ and 7F73, which correspond to approximately the same central meridian and distance from Mars (Figure 7). A large bright tongue (point 1 in frame 73) and a larger bright region near the limb (point 2) appear smaller and fainter in the Mariner 7 picture, despite the generally higher contrast of Mariner 7 FE frames. Much of the brightening near point 2 has disappeared entirely between the two flybys; in fact, it was not visible at all on pictures taken by Mariner 7 during the previous Mars rotation, although it was clearly visible in several Mariner 6 frames taken over the same range of distances. The bright tongue (point 1) increases in size and brightness during the martian day, as may be clearly seen from a comparison of frames 7F73 and 7F76 (Figure 7).
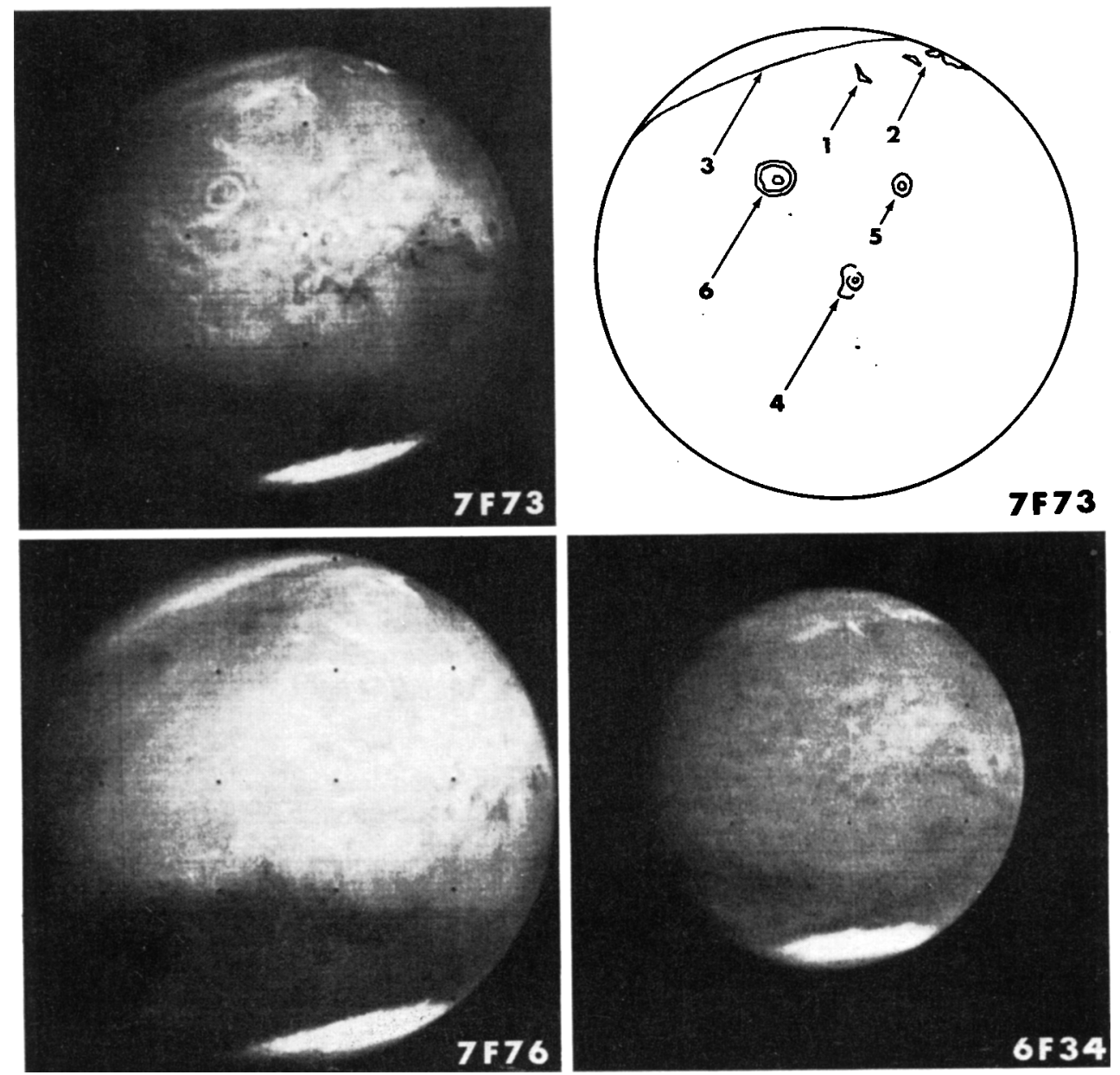

Fig. 7. Far-encounter pictures showing atmosphere and atmosphere-surface effects. Picture shutter times were as follows: 6F34, 30 July 0723 UT; 7F73, 4 August 1115 UT;

7F76, 4 August 1336 UT. 
The widespread, diffuse brightening covering much of the north polar cap region (point 3) apparently corresponds to the 'polar hood' which has been observed from the earth at this martian season (northern early autumn). The extent of this hood is smaller in Mariner 7 than in Mariner 6 pictures; the region between, and just north of, points 1 and 2 appears to be covered by the hood in the Mariner 6 frames, but shows no brightening in the Mariner 7 frames.

The different behaviors of the discrete bright regions and the hood suggest different origins for these features, although both apparently are either atmospheric phenomena or else result from the interaction of the atmosphere and the surface. The discrete bright regions have fixed locations suggesting either surface frost or orographically fixed clouds. The fluctuation in the areal extent of the diffuse hood suggests cloud or haze. An extensive cloud or haze composed of either $\mathrm{CO}_{2}$ or $\mathrm{CO}_{2}$ and $\mathrm{H}_{2} \mathrm{O}$ ice would be consistent with the atmospheric temperature structure revealed by the Mariner 6 occultation experiment [9].

\section{E. DIURNAL BRIGHTENING}

Other variable bright features which may be indicative of atmospheric processes appear throughout the Tharsis, Candor, Tractus Albus, and Nix Olympica regions (Figure 7, frame 7F73; see also [3]). The brightness of these areas is observed to develop during the forenoon and increase during the martian afternoon, both in the Mariner pictures and in photographs taken from the earth. The structure and locations in the FE pictures do not change over the 6-day time span during which the region was observed. Particularly striking are several long light streaks near Nix Olympica (point 6 in frame 7F73) and numerous circular features resembling craters, which have bright centers and dark edges. Several of the circular features exhibit one or more concentric circles similar to, but less striking than, those near Nix Olympica. Two features of this type form two of the westernmost points of the classical 'W-cloud' (points 4 and 5). No morphology associated with clouds - such as waves, billows, or cirriform streaks - appear in this region, although at the $30-\mathrm{km}$ resolution of these pictures such features would be visible in terrestrial clouds.

\section{F. SEARCH FOR LOCAL CLOUDS AND FOG}

All NE frames from both spacecraft were carefully examined for evidences of clouds or fog. Away from the south polar cap there are no evidences of such atmospheric phenomena. Over the polar cap and near its edge a number of bright features which may be atmospheric can be seen, although no detectable shadows are present and no local differences in height can be detected by stereoscopic viewing of overlapping regions whose stereo angles lie between $5^{\circ}$ and $12^{\circ}$. Little or no illumination is evident near and beyond the polar cap terminator. On the other hand, frames $7 \mathrm{~N} 11,12$, and 13 (Figure 8) show several diffuse bright patches suggestive of clouds near the polar cap edge. Also, on the cap itself a few local diffuse bright patches are present in frames 7N15 (green) and 7N17 (blue). Unlike most polar cap craters, which appear sharp and clear, a few crater rims and other topographic forms appear diffuse (frames 7 N17, 18, and 19). In frames 7N17 (blue) and 7N19 (green), remarkable curved, quasi-parallel 


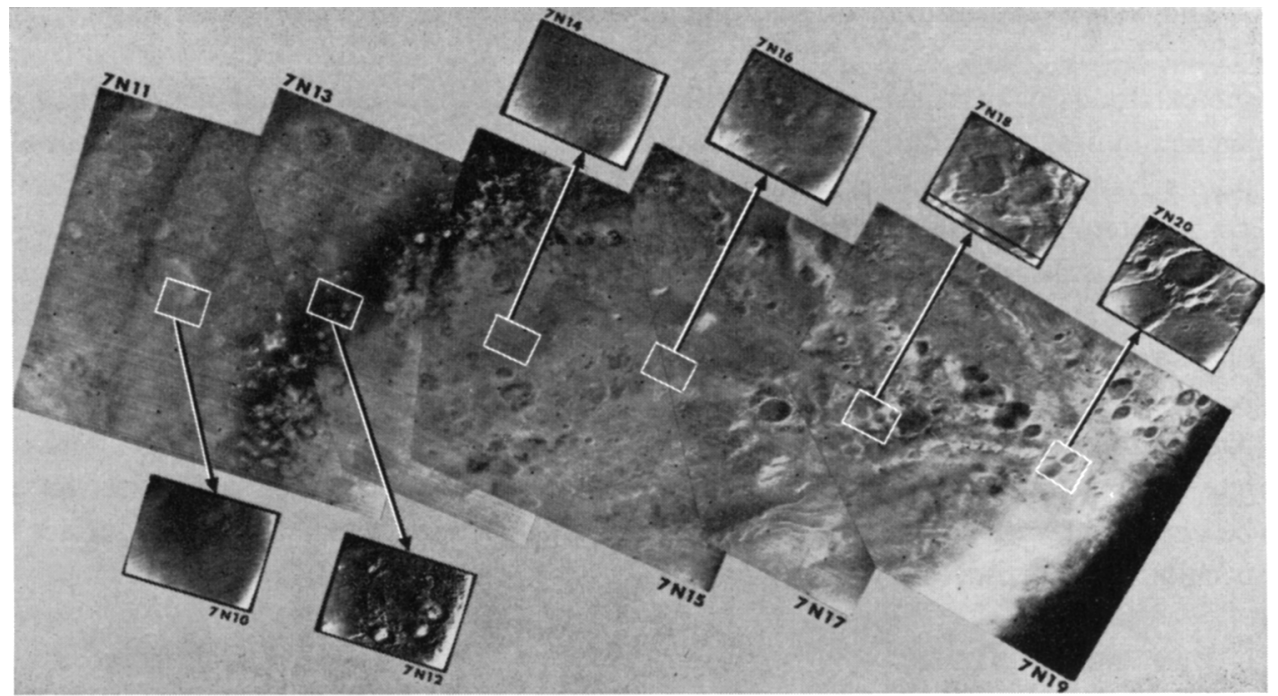

Fig. 8a. Composite of polar cap frames $7 \mathrm{~N} 10$ to $7 \mathrm{~N} 20$. Effects of AGC are clearly evident near the terminator (right) and at cap edge.

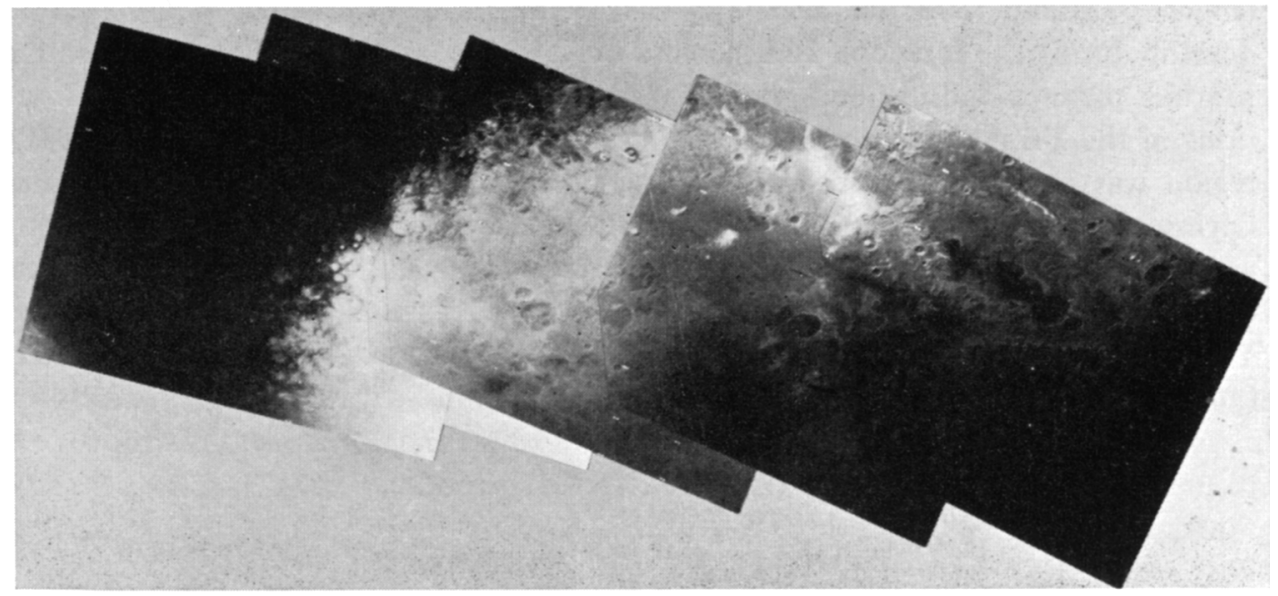

Fig. 8b. Composite of polar cap camera-A frames 7N11 to 7N19. The effects of AGC have been partially corrected, but contrast is enhanced. The south pole lies near the parallel streaks in the lower right corner of frame $7 \mathrm{~N} 17$.

bright streaks are visible near the south pole itself. While these show indications of topographic form or control, including some crater-like shapes, their possible cloudlike nature is suggested by lack of shading. Also frames $7 \mathrm{~N} 17$ and $7 \mathrm{~N} 19$ show faint but definite streaks and mottles very near the terminator, superimposed on a sparsely cratered surface.

\section{Observed Surface Features}

A primary objective of the Mariner 6 and 7 television experiment was to examine, at close range, the principal types of martian surface features seen from the earth. 
Mariners 6 and 7, while confirming the earlier evidence of a Moon-like cratered appearance for much of the martian surface, have also revealed significantly different terrains suggestive of more active, and more recent, surface processes than were previously evident. Preliminary analyses indicate that at least three distinctive terrains are represented in the pictures, as well as a mixture of permanent and transitory surface features displayed at the edge of, and within, the south polar cap; these terrains do not exhibit any simple correlation with the light and dark markings observed from the earth.

\section{A. CRATERED TERRAINS}

Cratered terrains are those parts of the martian surface upon which craters are the dominant topographic form (Figure 6). Pictures from Mariners 4, 6, and 7 all suggest that cratered terrains are widespread in the southern hemisphere.

Knowledge of cratered terrains in the northern hemisphere is less complete. Cratered areas appear in some Mariner frames as far north as latitude $20^{\circ}$. Nix Olympica, which in far-encounter photographs appears to be an unusually large crater, lies at $18^{\circ} \mathrm{N}$. Numerous craters are visible in the closer-range FE frames. These are almost exclusively seen in the dark areas lying in the southern hemisphere, few being visible in the northern hemisphere. This difference may result from an enhancement of crater visibility by reflectivity variations in dark areas. However, poor photographic coverage, highly oblique views, and unfavorable sun angles combine to limit our knowledge of the northern portion of the planet.

Preliminary measurements of the diameter-frequency distribution of martian craters in the region Deucalionis Regio were made on frames 6 N19 to 6 N22 and are shown in Figure $9 \mathrm{a}$. The curves are based upon 104 craters more than $0.7 \mathrm{~km}$ in diameter seen on frames $6 \mathrm{~N} 20$ and 22, and upon 256 craters more than $7 \mathrm{~km}$ in diameter seen on frames $6 \mathrm{~N} 19$ and 21. The most significant result is the existence of two different crater distributions, a dichotomy also apparent in morphology. The two morphological crater types are (i) large and flat-bottomed and (ii) small and bowl-shaped. Flatbottomed craters and most evident on frames $6 \mathrm{~N} 19$ and $6 \mathrm{~N} 21$. The diameters range from a few kilometers to a few hundred kilometers, with estimated diameter-todepth ratios on the order of 100 to 1 . The smaller, bowl-shaped craters are best observed in frames 6 N20 and 6 N22 and resemble lunar primary-impact craters. Some of them appear to have interior slopes steeper than 20 degrees.

The diameter-frequency distribution of large flat-bottomed craters is compared in Figure $9 \mathrm{~b}$ with the distribution of craters in the uplands on the far side of the moon near Tsiolkovsky. This particular lunar region was chosen for comparison because it is evidently a primordial surface, devoid of large post-upland features which might have modified the original crater distribution. The distribution of the small bowlshaped craters is compared in Figure 9c with the distribution of craters on the lunar maria [10]. The distribution curve for small martian craters larger than about $1 \mathrm{~km}$ in diameter has a slope of about -2 , which is similar to the curve for primary craters larger than $3 \mathrm{~km}$ in diameter on the lunar maria.

There are large variations in crater morphology among different cratered terrains. 


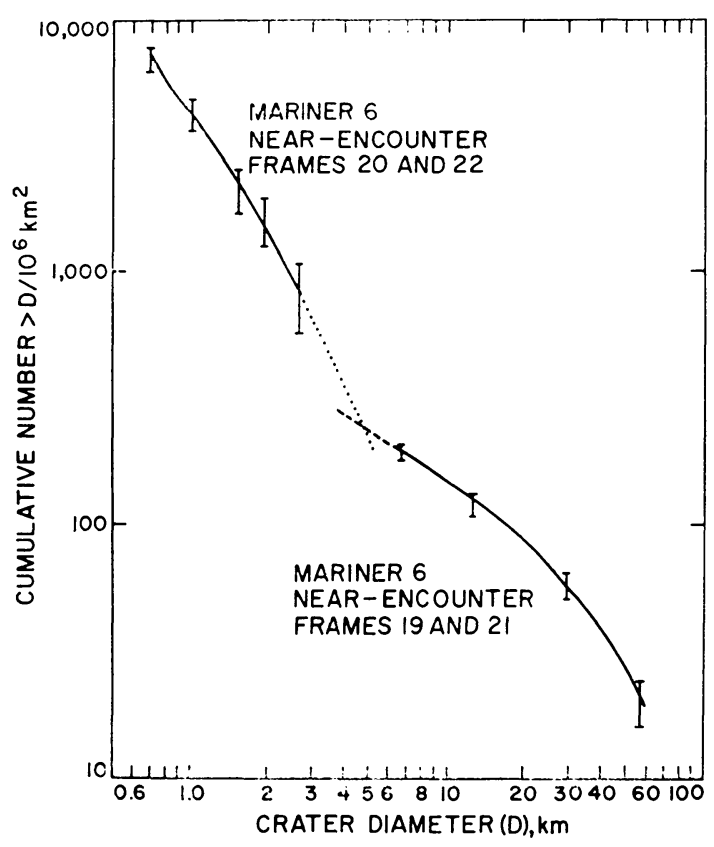

Fig. 9a. Preliminary cumulative distribution of crater diameters. Solid curve at right is based upon 256 counted craters in frames $6 \mathrm{~N} 19$ and $6 \mathrm{~N} 21$ having diameters $\geqslant 7 \mathrm{~km}$. The solid curve at left is based upon 104 counted craters in frames 6 N20 and 6 N22. The error bars are from counting statistics only $\left(N^{1 / 2}\right)$.

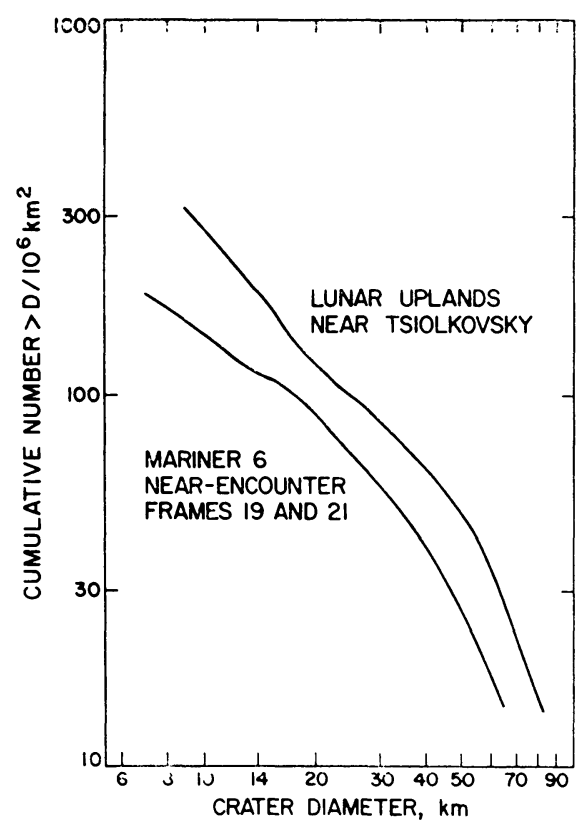

Fig. 9b. Comparison of size distribution of large craters on Mars and on the lunar uplands. 


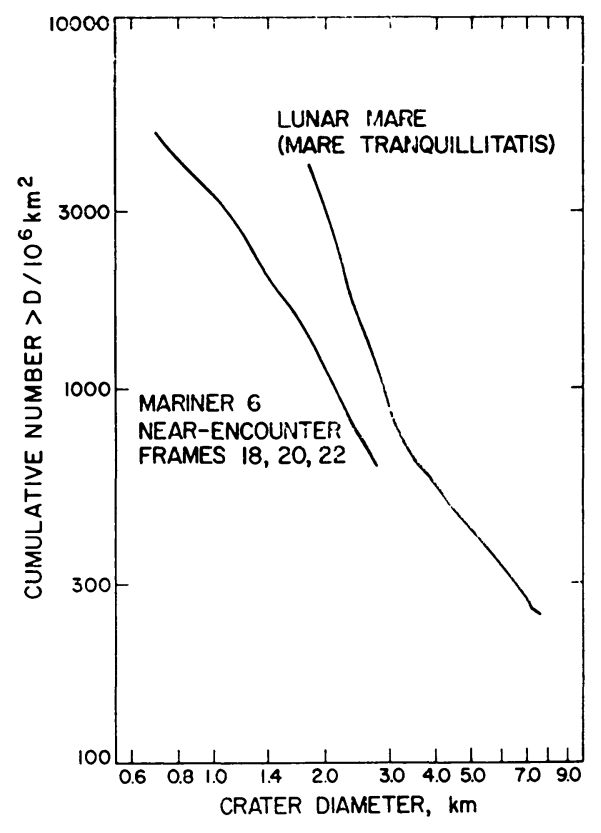

Fig. 9c. Comparison of size distribution of small craters on Mars and on a lunar mare.

The craters of the dark area Meridiani Sinus (Figure 6) have more marked polygonal outlines and more central peaks than craters in some other martian areas; the especially distinctive lighter marking in the northwest portions of the crater floors is also, but less clearly, seen in some FE frames. Many of the primary and secondary features associated with large lunar impact craters can be found on the martian terrain (see, for example, frame $6 \mathrm{~N} 18$ ); however, certain others, such as rays and secondary crater swarms, appear to be absent. Also, ejecta blankets appear to be much less well developed. The missing features are generally those most easily removed or hidden by erosion or blanketing - a pattern consistent with the observation that the martian craters are generally shallower and more smooth than lunar ones.

On frame 6 N20 there are low irregular ridges similar to those seen on the lunar maria. However, no straight or sinuous rills have been identified with confidence. Similarly, no earth-like tectonic forms possibly associated with mountain building, island-arc formation, or compressional deformation have been recognized.

\section{B. CHAOTIC TERRAINS}

Mariner frames 6 N6, 14, and 8 (Figure 10a) show two types of terrain - a relatively smooth cratered surface that gives way abruptly to irregularly shaped, apparently lower areas of chaotically jumbled ridges. This chaotic terrain seems characteristically to display higher albedo than its surroundings. On that basis, we infer that significant parts of the overlapping frames $6 \mathrm{~N} 5,7$, and 15 may contain similar terrain, although their resolution is not great enough to reveal the general morphological characteristics. 

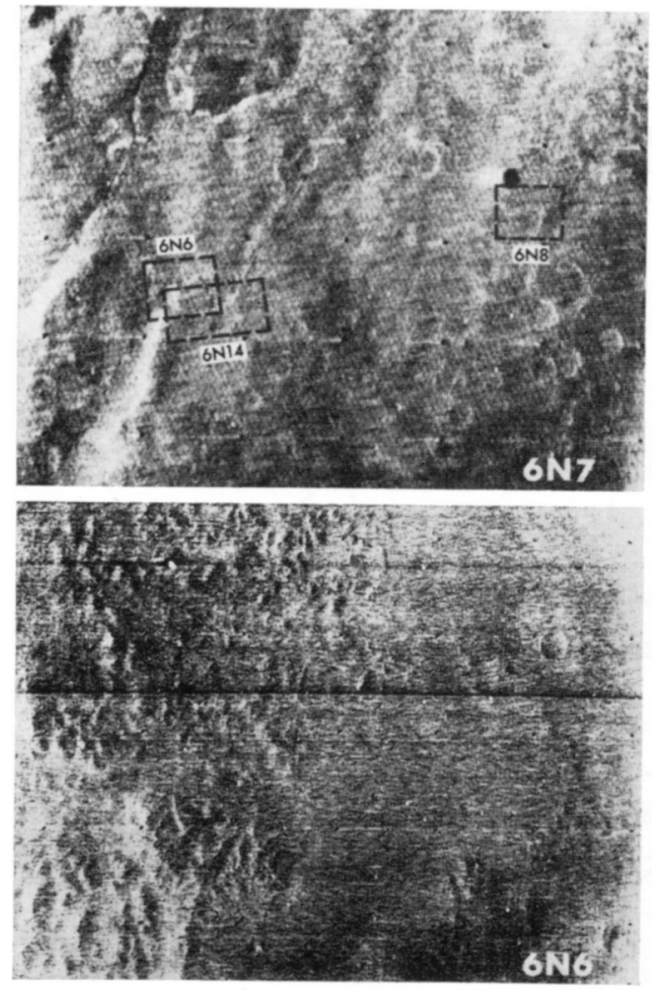
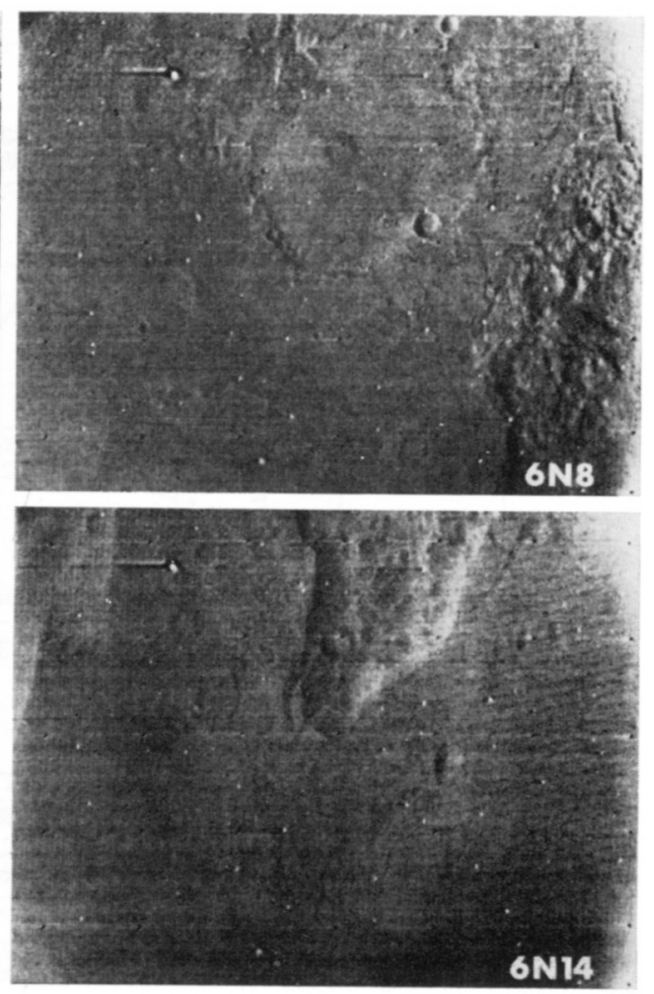

Fig. 10.

As shown in Figure 10a, frames 6N6, 14, and 8 all lie within frame 6N7, for which an interpretive map of possible chaotic terrain extent has been prepared (Figure 11).

About $10^{6} \mathrm{~km}^{2}$ of chaotic terrain may lie within the strip, $1000 \mathrm{~km}$ wide and $2000 \mathrm{~km}$ long, covered by these Mariner 6 wide-angle frames. Frames $6 \mathrm{~N} 9$ and 10 contain faint suggestions of similar features. This belt lies at about $20^{\circ} \mathrm{S}$, principally within the poorly defined, mixed light-and-dark area between the dark areas Aurorae Sinus and Margaritifer Sinus.

Chaotic terrain consists of a highly irregular plexus of short ridges and depressions, 1 to $3 \mathrm{~km}$ wide and 2 to $10 \mathrm{~km}$ long, best seen in frame 6N6 (Figure 10a). Although irregularly jumbled, this terrain is different in setting and pattern from crater ejecta sheets. Chaotic terrain is practically uncratered; only three faint possible craters are recognized in the $10^{6}-\mathrm{km}^{2}$ area. The patches of chaotic terrain are not all integrated, but they constitute an irregular pattern with an apparent $\mathrm{N}$ to $\mathrm{N} 30^{\circ} \mathrm{E}$ grain.

\section{FEATURELESS TERRAINS}

The floor of the bright circular 'desert', Hellas, centered at about $40^{\circ} \mathrm{S}$, is the largest area of featureless terrain so far identified. Even under very low solar illumination the area appears devoid of craters down to the resolution limit of about $300 \mathrm{~m}$. No area of comparable size and smoothness is known on the moon. It may be that all bright 


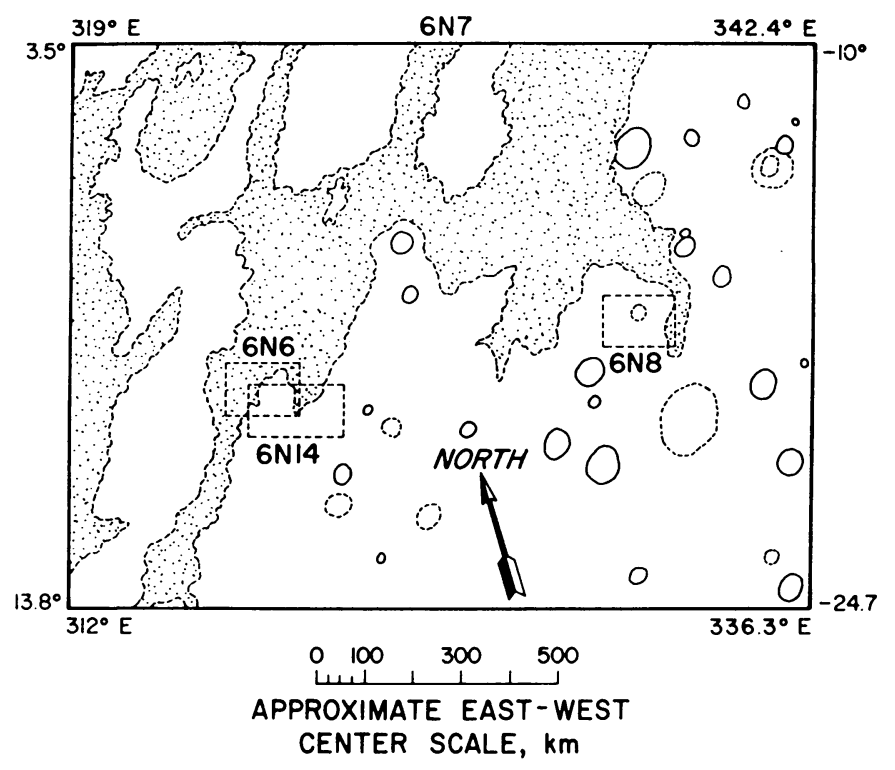

Fig. 11. Interpretive drawing showing the possible extent of chaotic terrain in frame 6 N7.

circular 'deserts' of Mars have smooth featureless floors; however, in the present state of our knowledge it is not possible to define any significant geographic relationship for featureless terrains.

The Mariner 7 traverse shows that the dark area Hellespontus, lying west of Hellas, is heavily cratered. The $130-$ to $350-\mathrm{km}$-wide transitional zone is also well cratered and appears to slope gently downward to Hellas, interrupted by short, en echelon scarps and ridges (Figure 12). It gives way abruptly along an irregular foot to the flat floor of Hellas. Craters are observed within the transitional zone but abruptly become obscured within the first $200 \mathrm{~km}$ toward the center of Hellas.

The possibility that a low haze or fog may be obscuring the surface of Hellas, and that the featureless images are therefore not relevant to the true surface, has been considered. However, in frame 7N26 the ridges of the Hellas-Hellespontus boundary are clearly visible, proving that the surface is seen; yet there are virtually no craters within that frame. Thus the absence of well-defined craters appears to be a real effect.

\section{SOUTH POLAR CAP FEATURES}

The edge of the martian south polar cap was visible at close range over a $90^{\circ}$ span of longitude, from $290^{\circ} \mathrm{E}$ to $20^{\circ} \mathrm{E}$, and the cap itself was seen over a latitude range from its edge, at $-60^{\circ}$, southward to, and perhaps beyond, the pole itself. Solar zenith angles ranged from $51^{\circ}$ to $90^{\circ}$ and more; the terminator is clearly visible in one picture. The phase angle for the picture centers was $35^{\circ}$. The superficial appearance is that of a clearly visible, moderately cratered surface covered with a varying thickness of 'snow'. The viewing angle and the unfamiliar surface conditions make quantitative comparison 


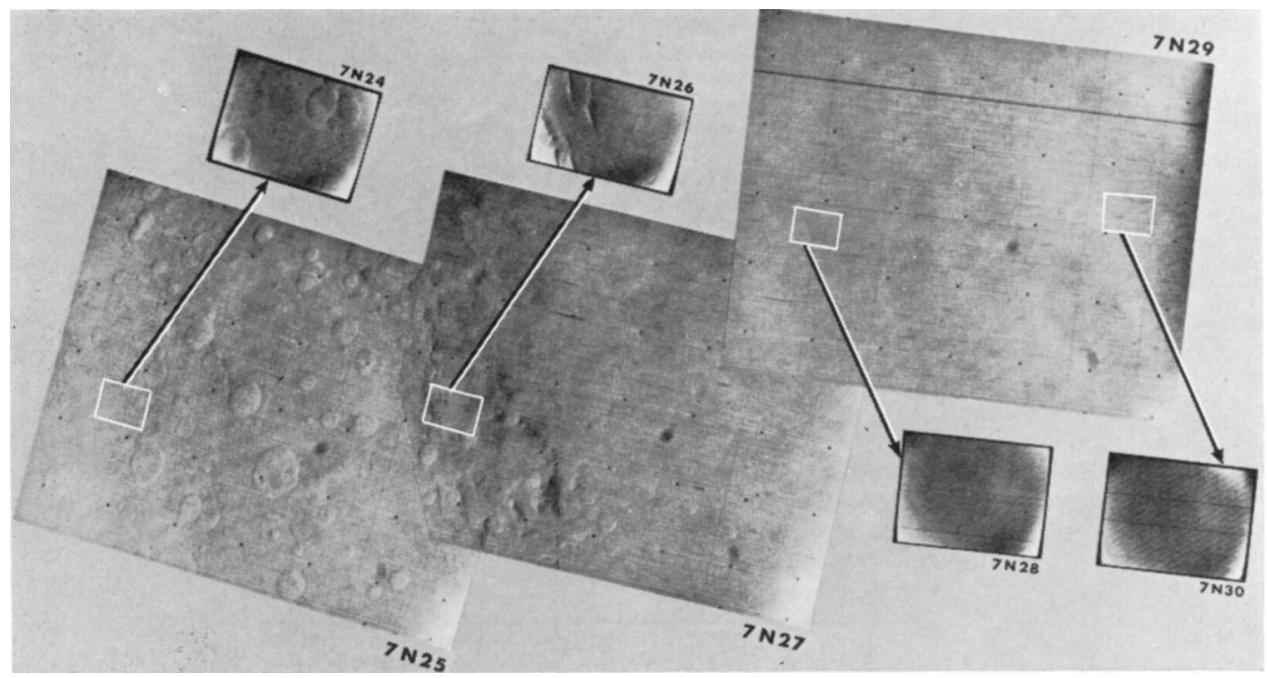

Fig. 12. Composite of seven Mariner 7 frames, showing the cratered dark area Hellespontus, the ridged, broken boundary between Hellespontus and Hellas, and the featureless terrain of the bright, circular 'desert' Hellas. Large-scale variations in contrast are suppressed by AGC. Lighting conditions are similar to those of Figure 6, frames 7N17 to 7N21. North is approximately toward the top.

with other areas of Mars difficult with respect to the number and size distributions of craters. Discussion here is therefore confined to those qualitative aspects of the polar cap which seem distinctive to that region.

The edge of the cap was observed in the FE pictures to be very nearly at $60^{\circ} \mathrm{S}$, as predicted from Lowell Observatory measurements [11]; this lends confidence to earthbased observations concerning the past behavior of the polar caps.

The principal effect seen at the cap edge is a spectacular enhancement of crater visibility and the subtle appearance of other topographic forms. In frames $7 \mathrm{~N} 11$ to $7 \mathrm{~N} 13$, where the local solar zenith angle was about $53^{\circ}$, craters are visible both on and off the cap. However, in the transition zone, about 2 degrees of latitude in width, the population density of visible craters is several times greater, and may equal any so far seen on Mars. This enhancement of crater visibility results mostly from the tendency, noted in Mariner 4 pictures 14 and 15, for snow to lie preferentially on poleward-facing slopes.

In frame $7 \mathrm{~N} 12$ the cap edge is seen in finer detail. The tendency mentioned above is here so marked as to cause confusion concerning the direction of the illumination. There are several tiny craters as small as $0.7 \mathrm{~km}$ in diameter, and areas of fine mottling and sinuous lineations are seen near the larger craters. The largest crater shows interesting grooved structure, near its center and on its west inner wall, which appears similar to that in frame $6 \mathrm{~N} 18$.

On the cap itself, the wide-angle views show many distinct reflectivity variations, mostly related to moderately large craters but not necessarily resulting from slopeillumination effects. Often a crater appears to have a darkened floor and a bright rim, 
and in some craters having central peaks the peaks seem unusually prominent. In frames 7 N17 and 7N19 several large craters seem to have quite dark floors.

In contrast, the high-resolution polar cap frames 7 N14 to 7 N20 suggest a more uniformly coated surface whose brightness variations are mostly due to the effects of illumination upon local relief. Several craters are visible in each frame, some quite small; but, unlike most other areas of Mars, regions of positive relief are also visible, notably in frames $7 \mathrm{~N} 14$ and $7 \mathrm{~N} 16$. Also distinctive in these frames are areas of fine, irregular, quasi-parallel bright boundaries and irregular, shallow depressed regions. In frame $7 \mathrm{~N} 14$, three such regions lie on the floor of a crater. Other irregular, shallow depressions apparently unrelated to craters appear in frames 7 N15 and 7 N17. Some of these are tens of kilometers in diameter and have no known counterparts elsewhere in the picture series of either spacecraft.

Finally, in frame 7N19 a curved, scalloped escarpment is seen, forming a boundary between a well-cratered area on its convex side and a relatively crater-free area on its concave side; this feature suggests the large circular structures associated with the mare basins on the moon.

\section{E. RELATIONSHIP OF TERRAIN TO LIGHT AND DARK MARKINGS}

The contrast of light and dark markings on Mars varies with wavelength, a fact long known from telescopic photography. In violet light, 'bright' and 'dark' areas are essentially indistinguishable, as they have approximately the same reflectivity. With increasing wavelength, contrast is enhanced as redder areas become relatively brighter. Frame 6N13 (Figure 6) shows craters in a dark area that have partially bright rims and floors, while craters in bright areas have rim and floor reflectivities similar to the reflectivity of the surroundings. These differences tend to increase the visibility of craters in dark areas, but only in photographs taken in red or green light. West of Meridiani Sinus (frames 6N9 and 6N11), and in some other parts of the planet, there are a number of dark-floored craters within bright areas, which, although otherwise relatively conspicuous, are difficult to see in blue light. The floors of these craters thus exhibit the same general dependence of reflectivity on wavelength that the larger dark areas do.

The distinction between bright and dark areas on the martian surface is generally more obvious in FE than in NE views. At higher resolution, the boundaries tend to become dispersed and indistinct. Exceptions are the sharp northeast and southern boundaries of Meridiani Sinus (frame 6N13) and the east edge of Hellespontus. The clearest structural relationship seen between a dark and a bright area is that of Hellespontus and Hellas (Figure 12).

Chaotic terrain appears to be lower and to have a somewhat higher reflectivity than adjacent cratered areas. Whether chaotic terrain is extensive enough to comprise any previously identified bright areas remains to be determined.

Some of the classical 'oases' observed from the earth have now been identified with single, large, dark-floored craters (such as Juventae Fons, see [4] and Figure 4) or groups of such craters (such as Oxia Palus, frame 7N5). At least two classical 'canals' (Cantabras and Gehon) have been found to coincide with quasi-linear 
alignment of several dark-floored craters, shown also in frame $7 \mathrm{~N} 5$ (Figure 13). As reported elsewhere [4], other canals are composed of irregular dark patches. It is probable that most canals will, upon closer inspection, prove to be associated with a variety of physiographic features, and that eventually they will be considered less distinctive as a class.

Some early drawings and 'maps' of Mars show a circular bright area within the dark area south of Syrtis Major and east of Sabaeus Sinus, very nearly in the place occupied by a large crater ([4] Figure 3; [12]). Further comparison of the Mariner pictures with early maps and photographs may prove fruitful in revealing long-term aspects of topographic associations of dark-area boundaries.

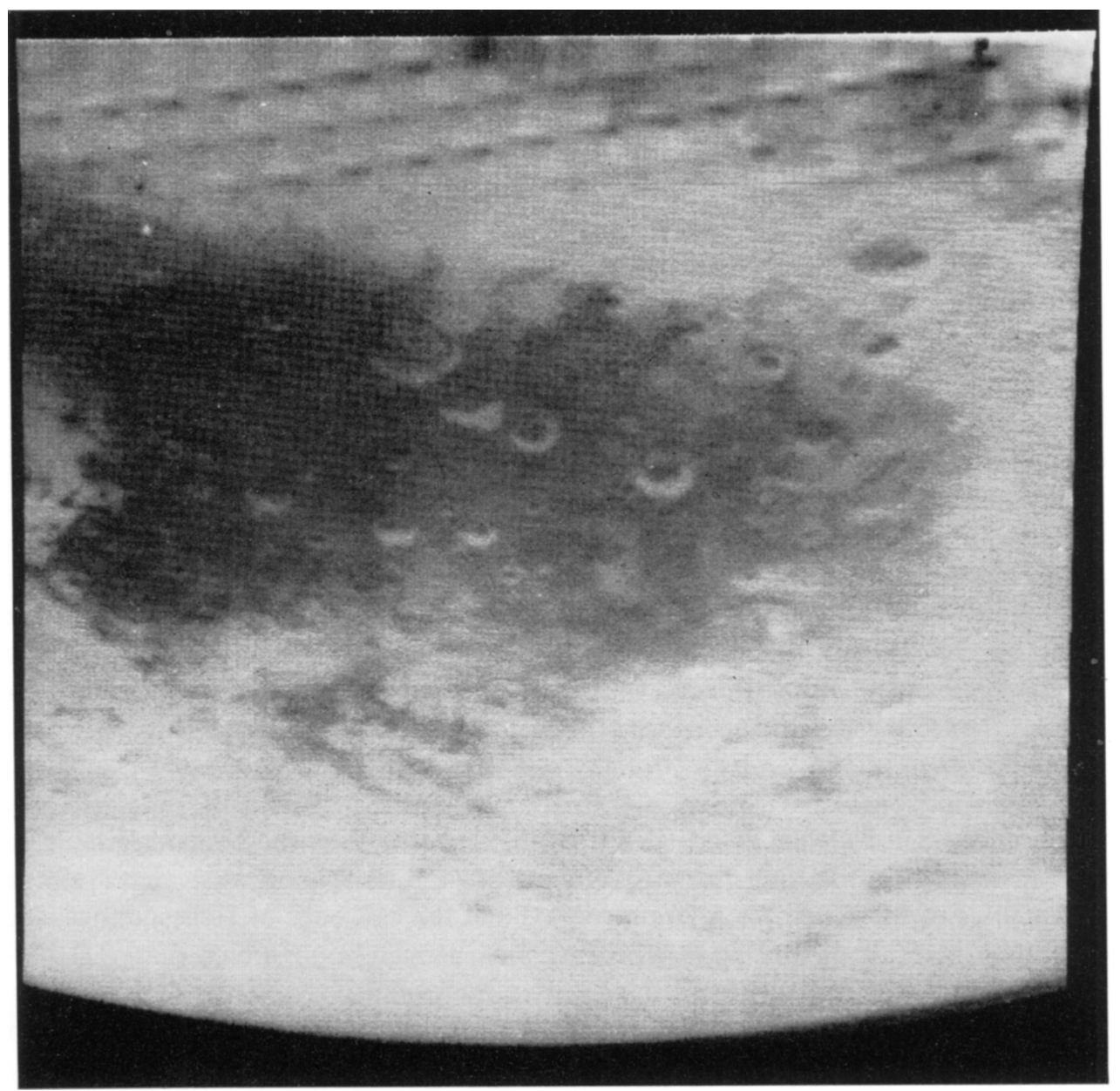

Fig. 13. Partially reconstructed frame 7N5, showing Meridiani Sinus in the foreground. The 'oasis' Oxia Palus projects into the picture from the left edge, near the limb. Note the asymmetric shading in several craters in Meridiani Sinus; the isolated, dark-floored craters in surrounding bright areas; and the crater complex in Oxia Palus. The view is approximately toward N $20^{\circ} \mathrm{W}$. The banded appearance of the sky area is an artifact of the picture processing. 
It is possible to make a few rough comparisons between the Mariner 6 and 7 pictures and estimates of Mars topographic elevations based on Mariner occultations [9], earth-based radar measurements [13], or $\mathrm{CO}_{2}$ equivalent-width spectral measurements [14].

The long stretch of cratered terrain in Deucalionis Regio (Figure 6) is located on what earth-based radar and $\mathrm{CO}_{2}$ measurements both suggest to be a very gradual slope rising westward. Here, at least, cratered terrain is not restricted to regionally high or to regionally low areas; like dark and light areas, it may not exhibit any particular correlation with planetary-scale relief.

The chaotic terrain viewed in Mariner 6 NE frames occurs in what appears to be the topographically lowest area surveyed by the spacecraft, if earth-based $\mathrm{CO}_{2}$ measurements are correct. Thus, it is at least possible that chaotic terrain is related in some consistent way to planetary-scale relief.

Mariner 7's occultation point occurred near Hellespontica Depressio, near latitude $55^{\circ} \mathrm{S}$, longitude $20^{\circ} \mathrm{E}$. A very low surface pressure was measured there, suggesting highly elevated terrain. If Hellespontica Depressio is elevated, Hellespontus may be also. This relationship would be consistent with the impression gained from the Mariner pictures that the floor of Hellas, with its featureless terrain, is a local basin rimmed by higher areas.

\section{Inferences concerning Processes and Surface History}

The features observed in the Mariner 6 and 7 pictures are the result of both present and past processes; therefore, they provide the basis of at least limited conjecture about those processes and their variations through time. In this section we consider the implications of (i) the absence of earth-like tectonic features; (ii) the erosion, blanketing, and secondary modification evidenced in the three principal terrains; and (iii) the probable role of equilibrium between $\mathrm{CO}_{2}$ solid and vapor in the formation of features of the south polar cap. We also consider the possible role of equilibrium between $\mathrm{H}_{2} \mathrm{O}$ solid and vapor as an explanation of the diurnal brightenings observed in the FE photographs and biological implications.

\section{A. SIGNIFICANCE OF THE ABSENCE OF EARTH-LIKE FORMS}

The absence of earth-like tectonic features on Mars indicates that, for the time period represented by the present large martian topographic forms, the crust of Mars has not been subjected to the kinds of internal forces that have modified, and continue to modify, the surface of the earth.

Inasmuch as the larger craters probably have survived from a very early time in the planet's history, it is inferred that Mars's interior is, and probably has always been, much less active than the earth's [15]. Furthermore, a currently held view [16] is that the earth's dense, aqueous atmosphere may have formed early, in a singular event associated with planetary differentiation and the origin of the core. To the extent, therefore, that surface tectonic features may be related in origin to the formation of a dense atmosphere, their absence on Mars independently suggests that Mars never had an earth-like atmosphere. 


\section{B. AGE IMPLICATIONS OF CRATERED TERRAINS}

At present, the ages of martian topographic forms can be discussed only by comparison with the moon. Both the moon and Mars exhibit heavily cratered and lightly cratered areas, which evidently reflect in each case regional differences in the history of, or the response to, meteoroidal bombardment over the total life-span of the surfaces. The existence of a thin atmosphere on Mars may have produced recognizable secondary effects in the form and size distribution of craters, by contrast with the moon, where a significant atmosphere has presumably never been present. To the extent that relative fluxes of large objects impinging upon the two bodies can be determined, or a common episodic history established, a valid age comparison may be hoped for, except in the extreme case of a saturated cratered surface, where only a lower limit to an age can be found.

It is a generally accepted view that the present crater density on the lunar uplands could not have been produced within the 4.5-billion-year age of the solar system had the bombardment rate been no greater than the estimated present rate; that is, the inferred minimum age is already much greater than is considered possible. Indeed, it is found that even the sparsely cratered lunar maria would have required about a billion years to attain their present crater density. Unless this discrepancy is somehow removed by direct measurements of the crystallization ages of returned samples of lunar upland and mare materials, the previously accepted implication of an early era of high bombardment followed by a long period of bombardment at a drastically reduced rate will presumably stand.

In the case of Mars, a bombardment rate per unit area as much as 25 times that on the moon has been estimated [17]. However, even this would still seem to require at least several billion years to produce the density of large craters that is seen on Mars in the more heavily cratered areas [15]. Thus these areas could also be primordial. Further, were these areas to have actually been bombarded at a constant rate for such a time, at least a few very recent, large craters should be visible, including secondary craters and other local effects. Instead, the most heavily cratered areas seem relatively uniform with respect to the degree of preservation of large craters, with no martian Tycho or Copernicus standing out from the rest. This again suggests an early episodic history rather than a continuous history for cratered martian terrain, and increases the likelihood that cratered terrain is primordial.

If areas of primordial terrain do exist on Mars, an important conclusion follows: these areas have never been subject to erosion by water. This in turn reduces the likelihood that a dense, earth-like atmosphere and large, open bodies of water were ever present on the planet, because these would almost surely have produced high rates of planet-wide erosion. On the earth, no topographic form survives as long as $10^{8} \mathrm{yr}$ unless it is renewed by uplift or other tectonic activity.

\section{IMPLICATIONS OF MODIFICATION OF TERRAIN}

Although erosional and blanketing processes on Mars have not been strong enough to obliterate large craters within the cratered terrains, their effects are easily seen. On frames $6 \mathrm{~N} 19$ and 6N21 (Figure 6), even craters as larger as 20 to $50 \mathrm{~km}$ in diameter 
appear scarce by comparison with the lunar uplands (a feature originally noted by Hartmann [15] on the basis of the Mariner 4 data), and the scarcity of smaller craters is marked. The latter have a relatively fresh appearance, however, which suggests an episodic history of formation, modification, or both. Such a history seems particularly indicated by the apparently bimodal crater frequency distribution of Figure 9.

Marked erosion, blanketing, and other surface processes must have been operating almost up to the present in the areas of featureless and chaotic terrains; only this could account for the absence of even small craters there. These processes may not be the same as those at work on the cratered terrains, because large craters have also been erased. The cratered terrains obviously have never been affected by such processes; this indicates an enduring geographic dependence of these extraordinary surface processes.

The chaotic terrain gives a general impression of collapse structures, suggesting the possibility of large-scale withdrawal of substances from the underlying layers. The possibility of permafrost some kilometers thick, and of its localized withdrawal, may deserve further consideration. Magmatic withdrawal or other near-surface disturbance associated with regional volcanism might be another possibility, but the apparent absence of extensive volcanic terrains on the surface would seem to be a serious obstacle to such an interpretation. It may also be that chaotic terrain is the product either of some unknown intense and localized erosional process or of unsuspected local sensitivity to a widespread process.

\section{CARBON DIOXIDE CONDENSATION EFFECTS}

The Mariner 7 NE pictures of the polar cap give no direct information concerning the material or the thickness of the polar snow deposit, since the observed brightness could be produced by a very few milligrams per square centimeter of any white, powdery material. However, they do provide important indirect evidence as to the thickness of the deposit and, together with other known factors, may help to establish its composition.

The relatively normal appearance of craters on the polar cap in the high-resolution frames, and the existence on these same frames of topographic relief unlike that so far recognized elsewhere on the planet, suggest that some of the apparent relief may be due to variable thicknesses of snow, perhaps drifted by wind. If it is, local thicknesses of at least several meters are indicated.

The structure of the polar cap edge shows that evaporation of the snow is strongly influenced by local slopes - that is, by insolation effects rather than by wind. On the assumption that the evaporation is entirely determined by the midday radiation balance, when the absorbed solar power exceeds the radiation loss at the appropriate frost-point temperature, one may estimate the daily evaporation loss from the cap. We find the net daily loss to be about $0.8 \mathrm{~g} / \mathrm{cm}^{2}$ in the case of $\mathrm{CO}_{2}$, although the loss is reduced by overnight recondensation. In the case of $\mathrm{H}_{2} \mathrm{O}$, the loss would be about 0.08 gram per square centimeter, and it would be essentially irreversible because $\mathrm{H}_{2} \mathrm{O}$ is a minor constituent whose deposition is limited by diffusion.

Since the complete evaporation of the cap at a given latitude requires many days, 
we may multiply the above rates by a factor between 10 and 100 , obtaining estimates for total cap thickness of tens of grams per square centimeter for $\mathrm{CO}_{2}$ and several grams per square centimeter for $\mathrm{H}_{2} \mathrm{O}$, on the assumption that the cap is composed of one or the other of these materials. The estimate for $\mathrm{CO}_{2}$ is quite acceptable, but that for $\mathrm{H}_{2} \mathrm{O}$ is unacceptable because of the problem of transporting such quantities annually from one pole to the other at the observed vapor density [18]. For the remainder of this discussion we assume the polar cap to be composed of $\mathrm{CO}_{2}$, with a few milligrams of $\mathrm{H}_{2} \mathrm{O}$ per square centimeter deposited throughout the layer.

Several formations have been observed which suggest a tendency for snow to be preferentially removed from low areas and deposited on high areas, contrary to what might be expected under quiescent conditions [19]. These formations include craters with dark floors and bright rims, prominent central peaks in some craters, and irregular depressed areas (frames $7 \mathrm{~N} 14,15$, and 17). While such effects might result simply from wind transport of solid material, it is also possible that interchange of solid and vapor plays a role.

The adiabatic lapse rate of the polar atmosphere is about $6 \mathrm{~K} / \mathrm{km}$, as compared to a frost-point lapse rate of about $1 \mathrm{~K} / \mathrm{km}$. Therefore, adiabatic heating or cooling of martian air blowing across sloping terrain may result in evaporation of low-lying solid and precipitation over high areas. The rate is determined by atmospheric density, latent heat, difference in elevation, lateral scale of relief, wind speed, turbulent-layer thickness, interfacial heat transfer, and net adiabatic gradient. For example, a wind of $20 \mathrm{~m} / \mathrm{sec}$ blowing across a crater $20 \mathrm{~km}$ in diameter and $0.5 \mathrm{~km}$ deep, with a turbulent layer only $100 \mathrm{~m}$ thick, could differentially deposit about $0.1 \mathrm{~g} / \mathrm{cm}^{2}$ per day. Since this process would be effective during the entire time that snow is on the ground, several tens of grams per square centimeter could become systematically redistributed in the course of a few hundred days. A speculative possibility is that such a process, or perhaps merely a sustained accumulation of snow in a particular topographic 'trap', occasionally results in sufficient accumulation during the winter to survive summer evaporation. The increased albedo might then lead to a permanent accumulation of $\mathrm{CO}_{2}$ snow within that topographic feature - that is, to formation of a martian 'ice field'. The very prominent snow-covered central peaks of some of the small craters located at high latitude might conceivably be the sites of such permanent deposits of solid $\mathrm{CO}_{2}$. The permanent part of the north polar cap is presumably such a structure [18].

\section{E. WATER: PROCESSES SUGGESTED BY BRIGHTENING PHENOMENA}

Several of the brightening and haze phenomena described above could be related either to formation of $\mathrm{H}_{2} \mathrm{O}$ frost on the surface or to formation of $\mathrm{H}_{2} \mathrm{O}$ ice clouds in the atmosphere. In most of these instances, however, the phenomena could equally well be explained by condensation of $\mathrm{CO}_{2}$. This is true of the bright tongues and polar hood in the north polar region, of the cloud-like features observed over and near the south polar cap, and of the limb hazes observed in tropical latitudes and over the Mare Hadriaticum and Ausonia regions.

On the other hand, the brightenings in the Nix Olympica. Tharsis, Candor. and 
Tractus Albus regions cannot be explained by $\mathrm{CO}_{2}$ condensation because their complete topographic control requires that they be on or near the surfaces where temperatures are well above the $\mathrm{CO}_{2}$ frost point. An explanation of these phenomena in terms of $\mathrm{H}_{2} \mathrm{O}$ condensation processes also faces serious difficulties, however. Most of the region is observed to brighten during the forenoon, when the surface is hotter than either the material below or the atmosphere above, so that water vapor could not diffuse toward the surface and condense on it, either from above or below. Thus a surface icefrost is very unlikely. A few features in the area, parts of the " $\mathrm{W}$-cloud', for example, are observed to brighten markedly during the late afternoon, where $\mathrm{H}_{2} \mathrm{O}$ frost could form on the surface if the air were sufficiently saturated. These features are not observed, from the earth, to be bright in the early morning, but a thin layer of $\mathrm{H}_{2} \mathrm{O}$ frost persisting through the night would evaporate almost immediately when illuminated by the early morning sun, provided the air were then sufficiently dry. Under these conditions, the behavior of the 'W-cloud' could be due to frost.

The diurnal behavior of the bright regions throughout this part of Mars is consistent with a theory of convective $\mathrm{H}_{2} \mathrm{O}$ ice clouds, but the absence of any cloud-like morphology and the clear topographic detail observed at the highest resolution available (frame 7F76) render this explanation questionable. Even very light winds of $5 \mathrm{~m} / \mathrm{sec}$ would produce easily observable displacements of the order of $100 \mathrm{~km}$ in the course of the more than one-fourth of the Mars day during which these regions were continuously observed by each spacecraft. Since condensation and evaporation processes are slow at Mars temperatures and pressures, some observable distortion and streakiness due to these displacements should be seen in clouds, even if they are orographically produced. No such distortions or streakiness are observed.

An additional difficulty with an explanation of these phenomena in terms of $\mathrm{H}_{2} \mathrm{O}$ condensation lies in the relatively rapid removal of water from the local surface. Water vapor evolved from the surface during the daytime would quickly be transported upward through a deep atmospheric layer by thermal convection, and most of it would be removed from the source region. Local permafrost sources should be effectively exhausted by this mechanism within a few hundred years at most, unless somehow replenished. Since most of this region lies near the equator, where seasonal temperature variations are small, it is difficult to see how any significant seasonal replenishment from the atmosphere could take place. The possibility of replenishment from a sub-surface source of liquid water is not considered here.

In summary, in our examination of the data thus far, we see no strong indications of $\mathrm{H}_{2} \mathrm{O}$ processes involving vapor and ice. The brightenings seen in the tropics and subtropics at far-encounter are not easily explained by a mechanism involving $\mathrm{H}_{2} \mathrm{O}$. On the other hand, we have no satisfactory alternative explanation for these phenomena. Perhaps detailed exploration of these regions by the Mariner ' 71 orbiters will provide the answer.

\section{F. BIOLOGICAL INFERENCES}

No direct evidence suggesting the presence of life on Mars has been found in the pictures. This is not surprising, since martian life, if any, would probably be microbial 20-P.A. 
and undetectable at a resolution of $300 \mathrm{~m}$. Although inconclusive on the question of martian life, the photographs are informative on at least three subjects of biological interest: the general nature of the martian maria, the present availability of water, and the availability of water in the past.

One of the most surprising results so far of the TV experiment is that nothing in the pictures suggests that the dark areas, the sites of the seasonal darkening wave, are more favorable for life than other parts of the planet. On the contrary, it would now appear that the large-scale surface processes implied by the chaotic and featureless terrains may be of greater biological interest than the wave of darkening. We reiterate that these are preliminary conclusions; it may be that subtle physiographic differences between dark and bright regions will become evident when photometrically corrected pictures are examined.

With regard to the availability of water, the pictures so far have not revealed any evidence of geothermal areas. We would expect such areas to be permanently covered with clouds and frost, and these ought to be visible on the morning terminator; no such areas have been seen. A classically described feature of the polar cap which has been interpreted as wet ground - the dark collar - has likewise not been found. Other locales which have been considered to be sites of higher-than-average moisture content are those which show diurnal brightening. A number of such places have been observed in the pictures, but on close inspection the brightening appears not to be readily interpretable in terms of water frosts or clouds. Pending their definite identification, however, the brightenings should be considered possible indications of water.

The results thus reinforce the conclusion, drawn from Mariner 4 and ground-based observations, that scarcity of water is the most serious limiting factor for life on Mars. No terrestrial species known to us could live in the dry martian environment. If there is a permafrost layer near the surface, or if the small amount of atmospheric water vapor condenses as frost in favorable sites, it is conceivable that, by evolutionary adaptation, life as we know it could use this water and survive on the planet. In any case, the continued search for regions of water condensation on Mars will be an important task for the 1971 orbiter.

The past history of water on Mars is a matter of much biological interest. According to current views, the chemical reactions which led to the origin of life on the earth were initiated in the reducing atmosphere of the primitive earth. These reactions produced simple organic compounds which were precipitated into the ocean, where they underwent further reactions that eventually yielded living matter. The pictorial evidence raises the question of whether Mars ever had enough water to sustain an origin of life. If the proportion of water outgassed relative to $\mathrm{CO}_{2}$ is the same for Mars as for the earth, then, from the mass of $\mathrm{CO}_{2}$ now in the martian atmosphere, it can be estimated that Mars has produced sufficient water to cover the planet to a depth of a few meters. The question is whether anything approaching this quantity of water was ever present on Mars in the liquid state.

The existence of cratered terrains and the absence of earth-like tectonic forms on Mars clearly implies that the planet has not had oceans of terrestrial magnitude for a 
very long time, possibly never. However, we have only very rough ideas of how much ocean is required for an origin of life, and of how long such an ocean must last. An upper limit on the required time, based on terrestrial experience, can be derived from the age of the oldest fossils, $>3.2 \times 10^{9}$ years [20]. Since these fossils are the remains of what were apparently highly evolved microorganisms, the origin of life must have taken place at a much earlier time, probably during the first few hundred million years of the earth's history. While one cannot rule out, on the basis of the TV data, the possibility that a comparably brief, aqueous epoch occurred during the early history of the planet, it must be said that the effect of the TV results so far is to diminish the a priori likelihood of finding life on Mars. However, it should be noted that if Mars is to be a testing ground for our notions about the origin of life, we must avoid using these same notions to disprove in advance the possibility of life on that planet.

\section{Potentialities of the Data}

Careful computer restoration of the pictures, starting with data recovered from six sequential playbacks of the near-encounter analog tapes, will be carried out over the next several months. This further processing will greatly enhance the completeness, appearance, and quantitative usefulness of the pictures. While it is not yet certain whether the desired 8-bit relative photometric accuracy can be attained, there are reasonable grounds for thinking that much new information bearing on the physiography, meteorology, geography, and other aspects of Mars will ultimately be obtained from the pictures. Some of the planned uses of the processed data are as follows.

\section{A. STEREOSCOPY}

Most of the NE wide-angle pictures contain regions of two-picture overlap, and a few contain regions of three-picture overlap. These areas can be viewed in stereoscopic vision in the conventional manner of aerial photography. Preliminary tests on pictures of the south polar cap (frames $7 \mathrm{~N} 17$ and $7 \mathrm{~N} 19$ ) indicate that measurement of crater depth, central-peak height, and crater-rim height is possible. However, accuracy can be estimated for the elevation determinations at this time.

\section{B. PLANETARY RADII}

Geometric correction of the FE photographs should make it possible to determine the radius of Mars as a function of latitude, and possibly of longitude. The geometric figure of Mars has been historically troublesome because of inconsistencies between the optical and the dynamical oblateness, a discrepancy amounting to some $18 \mathrm{~km}$ in the value for the difference of the equatorial and polar radii. It is possible that the darkening of the polar limb observed by Mariners 6 and 7, if it is a persistent phenomenon, might have systematically affected the earlier telescopic measurements of the polar diameter more than irradiation has, giving too large a value for the optical flattening. However, this cannot explain the large flattening obtained from surfacefeature geodesy [21]. Although a fairly reliable figure for the polar flattening may be obtained from the Mariner data, it is unlikely that the actual radii will be determined 
with an accuracy greater than several kilometers because of the relatively low pictureelement resolution in these frames and the difficulty in locating the limb.

\section{CARTOGRAPHY}

The large number of craters found on the surface of Mars makes it feasible to establish a control net which uses topographic features as control points, instead of surface markings based on albedo differences. This net should provide the basic locations for compiling a new series of Mars charts. The NE pictures, which cover 10 to $20 \%$ of the area of the planet, will constitute the basic material for detailed maps of these areas.

\section{SATELLITES}

We hope to detect the larger of Mars's satellites, Phobos, in two of the Mariner 6FE pictures taken when Phobos was just beyond the limb of the planet. The satellite should have moved between the two frames by about ten picture elements, and should appear as a 'defect' that has moved by this amount between the two pictures. If Phobos itself is not visible, its shadow (again detectable by its motion) should be. The shadow will be some five picture elements across and will have a photometric depth of about $10 \%$. If the photometric depth of the shadow can be measured accurately, we can determine the projected area (and hence the diameter) of the satellite. A similar method has been used to measure the diameter of Mercury during solar transits.

\section{E. PHOTOMETRIC STUDIES}

We expect to derive the photometric function for each color, combining data from the two spacecraft. Observations by the current Mariners were made near $25^{\circ}, 35^{\circ}, 45^{\circ}$, and $80^{\circ}$ phase. Since data obtained from the earth can be used to establish the absolute calibration at the smaller phase angles, we will also be able to relate the $80^{\circ}$-phase data to earth-based observations, thus doubling the range over which the phase function is determined. This information should then make possible the determination of crater slopes. Agreement for areas of overlap between different filters and between A-camera and B-camera frames can be used to check the validity of the results and possibly to measure and correct for atmospheric scattering.

The reciprocity principle may be useful in testing quantitatively for diurnal changes in the FE pictures. Such changes might include dissipation of frost or haze near the morning terminator and formation of afternoon clouds near the limb.

Overlap areas in NE pictures can be used to obtain approximate colors, even though these areas are seen at different phase angles in each color. In addition, color-difference or color-ratio pictures may be useful in identifying local areas of anomalous photometric or colorimetric behavior. Camera-A digital pictures obtained by Mariner 7 in late far-encounter will be very useful for making color measurements.

\section{F. COMPARISON OF PICTURES WITH RADAR-SCATTERING AND HEIGHT DATA}

The reflection coefficient of the martian surface for radar waves of decimeter wavelength shows marked variations at a given latitude as a function of longitude. Even though few of the areas of Mars so far observed by radar are visible at close range, 
some correlation of topography with radar reflectivity may become apparent upon careful study. Clearly, the Mariner pictures will become steadily more valuable in this connection as more radar results and other height data become available.

\section{Effects on Mariner '71}

The distinctive new terrains revealed in the Mariner 6 and 7 pictures, the relatively small fraction ( 10 to $20 \%$ ) of the surface so far viewed even at moderate (A-camera) resolution, and the tantalizing new evidence of afternoon-brightening phenomena all emphasize the importance of an exploratory, adaptive strategy in 1971 as opposed to a routine mapping of geographic features. The fact that each of three successive Mariner spacecraft has revealed a new and unexpected topography strongly suggests that more surprises (perhaps the most important ones) are still to appear.

A primary objective should be to view nearly all of the visible surface at A-camera resolution (1-km pixel spacing), and to inspect selected typical areas at higher resolution, very early in the 90-day orbiting period. The true extent and character of cratered, chaotic, and featureless terrains, and of any new kinds of terrain, can thus be determined and correlated with classical light and dark areas, with regional height data, and so on.

A second objective should be to search for and examine, in both spatial and temporal detail, those areas which suggest the local presence of water, through the afternoonbrightening phenomena, morning frosts or fogs, or other behavior not now recognized. Certainly the known 'W-cloud' areas, Nix Olympica, and other, similar areas known from earth observation take on a new interest by virtue of the Mariner 6 and 7 results.

The complex structure found in the south polar cap calls for further examination, particularly with respect to separation of its more permanent features from diurnally or seasonally varying ones. The sublimation of the cap should be carefully followed, so as to detect evidence of variations in thickness of the deposit and especially evidence of the possible existence of permanent deposits. Study of the north polar cap at close range should also be exceedingly interesting.

\section{Effects on Viking 73}

If the effects of the Mariner 6 and 7 results on Mariner ' 71 are substantial, they at least do not require a change of instrumentation, only one of mission strategy. This may not be true of the effects on Viking '73. The discovery of so many new, unexpected properties of the martian surface and atmosphere adds a new dimension to the problem of selecting the most suitable landing site and may make Viking even more dependent on the success of Mariner '71 than has been supposed. Furthermore, since so much new information is revealed through the tenfold step in resolution afforded by the B-camera frames, a further substantial increase in resolution, not available to Mariner '71, may have to be incorporated in Viking in order to examine even more closely the fine-scale characteristics of various terrain types before a landing site is chosen. 


\section{Summary and Conclusions}

Even in relatively unprocessed form, the Mariner 6 and 7 pictures provide fundamental new insights concerning the surface and atmosphere of Mars. Several unexpected results emphasize the importance of versatility in instrument design, flexibility in mission design, and use of an adaptive strategy in exploring planetary surfaces at high resolution.

The surface is clearly visible in all wavelengths used, including the blue. No blueabsorbing haze is found.

Thin, patchy, aerosol-scattering layers are present in the atmosphere at heights of from 15 to $40 \mathrm{~km}$, at several latitudes.

Diurnal brightening in the ' $\mathrm{W}$-cloud' area is seen repeatedly and is associated with specific topographic features. No fully satisfactory explanation for the effect is found.

Darkening of the polar cap in a band near the limb is clearly seen in FE pictures and is less distinctly visible in one or two NE frames. Localized, diffuse bright patches are seen in several places on and near the polar cap; these may be small, low clouds.

Widespread cratered terrain is seen, especially in dark areas of the southern hemisphere. Details of light-dark transitions are often related to local crater forms. Asymmetric markings are characteristic of craters in many dark areas; locally, these asymmetries often appear related, as if defined by a prevailing wind direction.

Two distinct populations of primary craters are present, distinguished on the basis of size, morphology, and age. An episodic surface history is indicated.

In addition to the cratered terrain anticipated from Mariner 4 results, at least two new, distinctive topographic forms are seen: chaotic terrains and featureless terrains. The cratered terrain is indicative of extreme age; the two new terrains both seem to require the present-day operation of especially active modifying processes in these areas. When seen at closer range, the very bright, streaked complex found in the Tharsis-Candor region may reveal yet another distinctive topographic character. Because of the afternoon-brightening phenomena long known here, this area provides a fascinating prospect for further exploration in 1971 .

No tectonic and topographic forms similar to terrestrial forms are observed.

Evidences of both atmosphere-surface effects and topographic effects are seen on the south polar cap. At the cap edge, where the 'snow' is thinnest, strong control by solar heating, as affected by local slopes, is indicated. Crater visibility is greatly enhanced in this area.

On the cap itself, intensity variations suggestive of variable 'snow' thickness are seen. These may be caused by wind-drifting of the snow or by differential exchange of solid and vapor, or by both.

Snow thicknesses here of several grams or several tens of grams per square centimeter are inferred if the snow material is $\mathrm{H}_{2} \mathrm{O}$ or $\mathrm{CO}_{2}$, respectively. The possibility that the material is $\mathrm{H}_{2} \mathrm{O}$ seems strongly ruled out on several grounds.

Variable atmospheric, and atmosphere-surface, effects are seen at high northern latitudes; these effects include the polar 'hood' and bright, diurnally variable circumpolar patches. 
Several classical features have been successfully identified with specific topographic forms, mostly craters or crater remnants.

The findings are inconclusive on the question of life on Mars, but they are relevant in several ways. They support earlier evidence that scarcity of water, past and present, is a serious limiting factor for life on the planet. Nothing so far seen in the pictures suggests that the dark regions are more favorable for life than other parts of Mars.

\section{Acknowledgments}

We gratefully acknowledge the support and encouragement of the National Aeronautics and Space Administration. An undertaking as complex as that of Mariners 6 and 7 rests upon a broad base of facilities, technical staff, experience, and management, and requires not only money but much individual and team effort to be brought to a successful conclusion. It is impossible to know, much less to acknowledge, the important roles played by hundreds of individuals. We are deeply appreciative of the support and efforts of H. M. Schurmeier and the entire Mariner 1969 project staff. With respect to the television system, responsibility for the design, assembly, testing, calibration, flight operation, and picture data processing lay with the Jet Propulsion Laboratory. We gratefully acknowledge the contributions of G. M. Smith, D. G. Montgomery, M. C. Clary, L. A. Adams, F. P. Landauer, C. C. LaBaw, T. C. Rindfleisch, and J. A. Dunne in these areas. L. Malling, J. D. Allen, and R. K. Sloan made important early contributions. We are indebted to V. C. Clarke, C. E. Kohlhase, R. Miles, and E. Greenberg for their help in exploiting the flexibility of the spacecraft to achieve maximum return of pictorial data. We are especially appreciative of the broad and creative efforts of G. E. Danielson as Experiment Representative. The able collaborative contributions of J. C. Robinson in comparing Mariner pictures with earth-based photographs and of L. A. Soderblom and J. A. Cutts in measuring craters are gratefully acknowledged.

\section{References}

[1] Leighton, R. B., Murray, B. C., Sharp, R. P., Allen, J. D., and Sloan, R. K.: 1965, Science 149, 627.

[2] Leighton, R. B., Murray, B. C., Sharp, R. P., Allen, J. D., and Sloan, R. K.: 1967, 'Mariner IV Pictures of Mars', Tech. Rept. Jet. Propul. Lab., Calif. Inst. Technol. No. 32-884, pt. 1.

[3] Leighton, R. B., Horowitz, N. H., Murray, B. C., Sharp, R. P., Herriman, A. G., Young, A. T., Smith, B. A., Davis, M. E., and Leovy, C. B.: 1969, Science 165, 684.

[4] Leighton, R. B., Horowitz, N. H., Murray, B. C., Sharp, R. P., Herriman, A. G., Young, A. T., Smith, B. A., Davis, M. E., and Leovy, C. B.: 1969, Science 165, 787.

[5] Montgomery, D. G.: in preparation.

[6] Danielson, G. E.: in preparation.

[7] Slipher, E. C.: 1937, Publ. Astron. Soc. Pacific 49, 137.

[8] Pollack, J. B. and Sagan, C.: 1969 Space Sci. Rev. 9, 243.

[9] Kliore, A. J., Fjeldbo, G., and Seidel, B.: in preparation.

[10] Trasle, M. J.: 1966, Tech. Rept. Jet. Propul. Lab. Calif. Inst. Technol. No. 32-800, p. 252.

[11] Fischbucher, G. E., Martin, L. J., and Baum, W. A.: 1969, 'Martian Polar Cap Boundaries', final report under Jet Propulsion Laboratory contract 951547, Lowell Observatory, May.

[12] Burgess, E.: private communication.

[13] Goldstein, R. M.: private communication; Councilman, C. C.: private communication. 
[14] Belton, M. J. S. and Hunten, D. M.: Science, in press.

[15] Hartmann, W. K.: 1966, Icarus 5, 565.

[16] Anderson, D. L. and Phinney, R. A.: 1967, in Mantles of the Earth and Terrestrial Planets (ed. by S. K. Runcorn), Interscience, New York, pp. 113-126.

[17] Anders, E. and Arnold, J. R.: 1965, Science 49, 1494.

[18] Leighton, R. B. and Murray, B. C.: 1966, Science 153, 136.

[19] O'Leary, B. T. and Rea, D. G.: 1967, Science 155, 317.

[20] Engel, A. E. J., Nagy, B., Nagy, L. A., Engel, C. G., Kremp, G. O. W., and Drew, C. M.: 1968, Science 161, 1005; Schopf, J. W. and Barghoorn, E. S.: 1967, Science 156, 508.

[21] Trumpler, R. J.: 1927, Lick Obs. Bull. 13, 19. 